\title{
Article \\ Photocatalytic Conversion of Organic Pollutants in Air: Quantum Yields Using a Silver/Nitrogen/TiO 2 Mesoporous Semiconductor under Visible Light
}

\author{
Adilah Sirivallop ${ }^{1,2}$, Salvador Escobedo ${ }^{3}$, , Thanita Areerob ${ }^{4}$, Hugo de Lasa ${ }^{3, *}$ and Siriluk Chiarakorn ${ }^{5, *(D)}$ \\ 1 Division of Environmental Technology, The Join Graduate School of Energy and Environment, \\ King Mongkut's University of Technology Thonburi, Bangkok 10140, Thailand; adey.siriwallop@gmail.com \\ 2 Center of Excellence on Energy Technology and Environment (CEE), PERDO, Ministry of Higher Education, \\ Science, Research, and Innovation, Bangkok 10140, Thailand \\ 3 Chemical Reactor Engineering Centre (CREC), Department of Chemical and Biochemical Engineering, \\ Faculty of Engineering, University of Western Ontario, London, ON N6A 5B9, Canada; sescobe@uwo.ca \\ 4 Faculty of Technology and Environment, Phuket Campus, Prince of Songkla University, \\ Phuket 83120, Thailand; Thanita.a@phuket.psu.ac.th \\ 5 Environmental Technology Program, School of Energy, Environment and Materials, \\ King Mongkut's University of Technology Thonburi, Bangkok 10140, Thailand \\ * Correspondence: hdelasa@uwo.ca (H.d.L.); siriluk.chi@kmutt.ac.th (S.C.)
}

check for updates

Citation: Sirivallop, A.; Escobedo, S.; Areerob, T.; de Lasa, H.; Chiarakorn, S. Photocatalytic Conversion of Organic Pollutants in Air: Quantum Yields Using a Silver/Nitrogen $/ \mathrm{TiO}_{2}$ Mesoporous Semiconductor under Visible Light. Catalysts 2021, 11, 529 https://doi.org/10.3390/ catal11050529

Academic Editor: Ewa Kowalska

Received: 30 March 2021

Accepted: 19 April 2021

Published: 21 April 2021

Publisher's Note: MDPI stays neutral with regard to jurisdictional claims in published maps and institutional affiliations.

Copyright: (c) 2021 by the authors. Licensee MDPI, Basel, Switzerland. This article is an open access article distributed under the terms and conditions of the Creative Commons Attribution (CC BY) license (https:// creativecommons.org/licenses/by/ $4.0 /)$.

\begin{abstract}
This research studies the photocatalytic conversion of methanol (25-90 $\mu \mathrm{mol} / \mathrm{L}$ range $)$ as a volatile organic compound (VOC) surrogate into $\mathrm{CO}_{2}$, using a N/Ag/ $\mathrm{TiO}$, photocatalyst under visible light irradiation in a Photo-CREC Air unit. The N/Ag/ $\mathrm{TiO}_{2}$ mesh supported photocatalyst is prepared via the solvothermal method. While the bare- $\mathrm{TiO}_{2}$ is inactive under visible light, the $\mathrm{N} / \mathrm{Ag} / \mathrm{TiO}_{2} 2 \mathrm{wt} . \%$ loaded stainless-steel woven mesh displays 35\% quantum yields, with $80 \%$ absorbed photons and 60\% methanol conversion in a $110 \mathrm{~min}$ irradiation period. Results obtained are assigned to silver surface plasmon resonance, silver and nitrogen species synergistic impacts on band gap, and their influence on particle agglomerate size and semiconductor acidity. The determined quantum yields under visible light in a Photo-CREC Air unit, are the highest reported in the technical literature, that these authors are aware of, with this opening unique opportunity for the use of visible light for the purification of air from VOC contaminants.
\end{abstract}

Keywords: photocatalysis; methanol; silver and nitrogen; titanium dioxide; visible light

\section{Introduction}

Methanol is a toxic alcohol and a major volatile organic compound (VOC). It has been listed, since 1990, by the Environmental Protection Agency (EPA), as a hazardous air pollutant (HAPs) [1]. Methanol is primarily used as a chemical and solvent for industrial production, as well as an alternative fuel source for automobiles [2]. Methanol is mostly emitted from industrial solvent utilization facilities. This constitutes approximately $34 \%$ of all the emission sources from industry. Methanol has a high toxicity for humans [3]. It is readily absorbed into the body through inhalation, ingestion, and skin contact, and can cause blindness, headache, and nausea [4]. Moreover, large methanol doses may cause unconsciousness, coma and possible death due to respiratory failure [5]. In addition, the oxidation products of methanol, such as formaldehyde and formic acid, are carcinogenic to humans [6]. Consequently, the removal of methanol and its oxidation derivatives is critical to control air quality, in the industrial settings where there is frequent usage of these chemicals.

In recent years, photocatalysis has been shown to be one of the most efficient oxidation processes for the mineralization of numerous organic pollutants, especially those designated as VOCs [7-9]. Photocatalysis is considered to be a simple, sustainable technology, 
which can be successfully applied to the degradation of air pollutants at room temperature, with a modest energy requirement [10]. Regarding possible photocatalysts, titanium dioxide $\left(\mathrm{TiO}_{2}\right)$ is the most promising semiconductor, given that it can be widely used for air purification applications, and given that it is highly chemically stable, inexpensive, and safe for use by humans [11].

However, the demonstrated activity of current photocatalysts, as shown via quantum yields (QYs) is still limited. This is given the properties of available semiconductors such as rapid charge recombination, low surface area, and high band gap (3.20 eV) [9]. To circumvent this, research is currently being conducted to develop a mesoporous $\mathrm{TiO}_{2}$ photocatalyst $[12,13]$ which can be used with near-ultraviolet (near-UV) light for wastewater treatment [14-18]. Nevertheless, these materials have not been investigated thoroughly for air treatment in the context of reaction engineering principles [19]. In particular, there is no information in the current open technical literature that we are aware of, about QYs for VOCs degradation under visible light.

$\mathrm{TiO}_{2}$ property modification have been achieved by doping/co-doping metals and nonmetals in a $\mathrm{TiO}_{2}$ crystal lattice [20]. Among all metals and non-metals, silver and nitrogen doping into a $\mathrm{TiO}_{2}$ crystal lattice has shown great promise for visible light photocatalytic activity $[14,21]$. In this respect, silver doping narrows the band gap energy as shown via surface plasmon resonance (SPR). Also, silver can act as an electron sink to store electrons $\left(e^{-}\right)$on a $\mathrm{TiO}_{2}$ surface, thus reducing electron availability and/or delaying electron $\left(e^{-}\right)$ and hole $\left(\mathrm{h}^{+}\right)$recombination. In addition, incorporating nitrogen into a $\mathrm{TiO}_{2}$ lattice has been shown to reduce the band gap energy by creating a new-mid band above the valence band. Furthermore, as reported recently by Sirivallop et al., (2020). the co-doping of silver and nitrogen in $\mathrm{TiO}_{2}$ creates a synergistic effect, leading to enhanced photocatalytic activity under visible light [13].

It should be mentioned that the Photo-CREC-Air Reactor designed by the CREC (Chemical Reactor Engineering Centre), at the University of Western Ontario, Canada, offers special features for VOCs conversion. In this respect, Garcia-Hernandez et al. [22] and LugoVega et al. [15] achieved the complete photoconversion of several volatile organic pollutants (such as acetone, acetaldehyde and formaldehyde) using a Degussa P25 photocatalyst under near-UV light, in the Photo-CREC-Air Reactor. This was achieved with very high QYs surpassing the $100 \%$ level.

Nevertheless, there is still a need to investigate VOCs conversion in a Photo-CRECAir unit and to establish QYs using semiconductors which are active under visible light. Despite of its great importance, this significant topic remains unaddressed in the open technical literature [10]. The present research highlights the value of reducing VOCs in indoor spaces by using solar light, free of any energy expense, together with a photocatalyst. To accomplish this, in the present study, the photocatalytic conversion of a surrogate VOC species (methanol) using a mesoporous 5.6 at $\% \mathrm{~N} / \mathrm{Ag}$ in $\mathrm{TiO}_{2}$ is reported [13]. The valuable results obtained show that significant methanol conversions with high QYs can be achieved in a Photo-CREC-Air unit using the mesoporous $\mathrm{N} / \mathrm{Ag} / \mathrm{TiO}_{2}$ photocatalyst.

\section{Photocatalytic Mechanism of Methanol}

The photocatalytic reaction mechanism of methanol can be envisioned as reported by de Lasa et al. [19] as a series of steps leading to the formation of hydroxyl $\left(\mathrm{OH}^{\bullet}\right)$ radicals as follows:

Step. 1 Photons with the adequate energy induce the formation of an electron and a positive hole $\left(\mathrm{h}^{+}\right)$:

$$
\text { Photocatalysts } \stackrel{\mathrm{hv}}{\rightarrow} \mathrm{e}_{\mathrm{cb}}^{-}+\mathrm{h}_{\mathrm{vb}}^{+}
$$

Step. 2 The hydroxyl radicals $\left(\mathrm{OH}^{\bullet}\right)$ are formed as follows:

(2.1) Reaction between $\mathrm{H}_{2} \mathrm{O}$ and hole $\left(\mathrm{h}^{+}\right)$

$$
2 \mathrm{~h}_{\mathrm{vb}}^{+}+2 \mathrm{H}_{2} \mathrm{O}_{\mathrm{ads}} \rightarrow 2 \mathrm{OH}_{\mathrm{ads}}^{\bullet}+2 \mathrm{H}_{\mathrm{ads}}^{+}
$$




$$
2 \mathrm{~h}_{\mathrm{vb}}^{+}+2 \mathrm{OH}_{\mathrm{ads}}^{-} \rightarrow 2 \mathrm{OH}_{\mathrm{ads}}^{\bullet}
$$

(2.2) Reaction between $\mathrm{O}_{2}$ and electron $\left(\mathrm{e}^{-}\right)$

$$
\begin{gathered}
\mathrm{e}_{\mathrm{cb}}^{-}+\mathrm{O}_{2 \mathrm{ads}} \rightarrow \mathrm{O}_{2 \mathrm{ads}}^{-\bullet} \\
\mathrm{O}_{2 \mathrm{ads}}^{-\bullet}+2 \mathrm{H}_{\mathrm{ads}}^{+} \rightarrow \mathrm{H}_{2} \mathrm{O}_{2 \mathrm{ads}} \\
\mathrm{H}_{2} \mathrm{O}_{2 \mathrm{ads}}+\mathrm{e}_{\mathrm{cb}}^{-} \rightarrow \mathrm{OH}_{\text {ads }}^{\bullet}+\mathrm{OH}_{\mathrm{ads}}^{-} \\
\mathrm{H}_{2} \mathrm{O}_{2 \mathrm{ads}} \stackrel{\text { hv }}{\rightarrow} 2 \mathrm{OH}_{\mathrm{ads}}^{\bullet}
\end{gathered}
$$

Thus, this leads to an overall stoichiometry to produce $\mathrm{OH}^{\bullet}$ as proposed as in Equation (8):

$$
\mathrm{O}_{2 \mathrm{ads}}+2 \mathrm{H}_{2} \mathrm{O}_{\text {ads }} \stackrel{3 \mathrm{hv}}{\rightarrow} 4 \mathrm{OH}_{\text {ads }}^{\bullet}
$$

Step. 3 In the case of organic species in water, methanol $\left(\mathrm{CH}_{3} \mathrm{OH}\right)$ is progressively oxidized via a sequence of steps ending with the formation of $\mathrm{CO}_{2}$ as follows:

$$
\begin{gathered}
\mathrm{CH}_{3} \mathrm{OH}+\mathrm{OH}^{\bullet} \rightarrow \mathrm{CH}_{2} \mathrm{OH}+\mathrm{H}_{2} \mathrm{O} \\
\mathrm{CH}_{2} \mathrm{OH}+\mathrm{OH}^{\bullet} \rightarrow \mathrm{HCHO}+\mathrm{H}_{2} \mathrm{O} \\
\mathrm{HCHO}+2 \mathrm{OH}^{\bullet} \rightarrow \mathrm{HCOOH}+\mathrm{H}_{2} \mathrm{O} \\
\mathrm{HCOOH}+2 \mathrm{OH}^{\bullet} \rightarrow \mathrm{CO}_{2}+2 \mathrm{H}_{2} \mathrm{O}
\end{gathered}
$$

As a result, and assuming complete methanol conversion into $\mathrm{CO}_{2}$, and adding Equations (9)-(12) gives the following equation:

$$
\mathrm{CH}_{3} \mathrm{OH}+6 \mathrm{HO}^{\bullet} \rightarrow \mathrm{CO}_{2}+5 \mathrm{H}_{2} \mathrm{O}
$$

Thus, and because of the postulated reaction mechanism, one can conclude that: (a) the photocatalytic reaction, as described via Equations (1)-(7), leads to an overall stoichiometry where 3 photons form $4 \mathrm{OH}^{\bullet}$ groups (de Lasa et al. [19]) and (b) the complete methanol conversion into $\mathrm{CO}_{2}$ requires $6 \mathrm{OH}^{\bullet}$ groups to be consumed per every $\mathrm{CO}_{2}$ molecule formed.

\section{Results and Discussions}

\subsection{Properties of the Prepared Photocatalysts}

The synthesized titanium dioxide-nitrogen-silver $\left(\mathrm{N} / \mathrm{Ag} / \mathrm{TiO}_{2}\right)$ photocatalyst and the bare- $-\mathrm{TiO}_{2}$ were characterized as reported in Table 1. It was found that the bare- $\mathrm{TiO}_{2}$ has a surface area and pore volume of only $11.6 \mathrm{~m}^{2} \cdot \mathrm{g}^{-1}$ and $0.02 \mathrm{~cm}^{3} \cdot \mathrm{g}^{-1}$, respectively. However, given that the $\mathrm{N} / \mathrm{Ag} / \mathrm{TiO}_{2}$ photocatalyst has a mesoporous character, the surface area and pore diameter significantly increased to $101.3 \mathrm{~m}^{2} \cdot \mathrm{g}^{-1}$ and $0.26 \mathrm{~cm}^{3} \cdot \mathrm{g}^{-1}$, respectively. These two parameters were around 10 times larger than those of bare- $\mathrm{TiO}_{2}$. This seems to be caused by the $\mathrm{N}$ and $\mathrm{Ag}$ species influence on the $\mathrm{TiO}_{2}$ crystal lattice as further described in Appendix D.

The crystal structure and the crystallite sizes of the photocatalysts were investigated using the XRD spectra (JCPDS card No. 21-1272) for anatase (101) bare- $\mathrm{TiO}_{2}$ [26], as shown in Figure 1a. This showed that the $\mathrm{N} / \mathrm{Ag} / \mathrm{TiO}_{2}$ photocatalyst is composed of an anatase crystal phase like that of the mesoporous bare- $\mathrm{TiO}_{2}[27,28]$. For additional XRD results for the $\mathrm{N} / \mathrm{Ag} / \mathrm{TiO}_{2}$, refer to Sirivallop et al. [13]. The crystallite sizes of the anatase (101) bare- $\mathrm{TiO}_{2}$ were calculated using the Debye-Scherrer's formula (see Equation (14)) [29-31]. This showed that the $\mathrm{N} / \mathrm{Ag} / \mathrm{TiO}_{2}$ powder involves $11.4 \mathrm{~nm}$ crystallites which are smaller than the $61.4 \mathrm{~nm}$ crystallites of the bare- $\mathrm{TiO}_{2}$ (Table 1). The smaller crystallite size of the $\mathrm{N} / \mathrm{Ag} / \mathrm{TiO}_{2}$ is assumed to be caused by the influence of the $\mathrm{N}$ and $\mathrm{Ag}$ species doping under the solvothermal conditions, which limit the anatase crystal grain growth. This is in agreement with Yang et al. [32] and others, concluding that the anatase crystal size can be 
controlled by incorporating metals via the solvothermal method [16,33-35]. In addition, one can also observe that the grain size reduction justifies the enhanced $\mathrm{N} / \mathrm{Ag} / \mathrm{TiO}_{2}$ specific surface area. Furthermore, the change in the crystallite volume as well as the change in the density of a unit cell can be attributed to the influence of $\mathrm{N}$ and Ag loadings on the bare photocatalyst [36]. However, one can note that the increase in external agglomerate specific surface (Table 1) of the $\mathrm{N} / \mathrm{Ag} / \mathrm{TiO}_{2}$, as compared with the bare- $\mathrm{TiO}_{2}$, can have a negative effect on the photocatalytic reaction as observed later in this study, under near-UV and claimed by others [37].

Table 1. Characteristic properties of the synthesized $\mathrm{TiO}_{2}$ and $\mathrm{N} / \mathrm{Ag} / \mathrm{TiO}_{2}$ photocatalysts.

\begin{tabular}{|c|c|c|c|c|c|c|c|c|}
\hline Samples & $\begin{array}{c}\text { Crystal } \\
\text { Phase } \\
(\%)\end{array}$ & $\begin{array}{l}\text { Crystal Size } \\
\quad(n m)^{a}\end{array}$ & $\begin{array}{c}\text { Average } \\
\text { Agglomerate } \\
\text { Size }(\mathrm{nm})^{\mathbf{b}}\end{array}$ & $\frac{\rho_{\mathrm{p}}}{\left(\mathrm{g} \cdot \mathrm{cm}^{-3}\right)^{\mathrm{c}}}$ & $\begin{array}{c}\text { External } \\
\text { Agglomerate } \\
\text { Specific Surface } \\
\left(\mathrm{m}^{2} \cdot \mathrm{g}^{-1}\right)^{d}\end{array}$ & $\begin{array}{c}\mathrm{S}_{\mathrm{BET}} \\
\left(\mathrm{m}^{2} \cdot \mathrm{g}^{-1}\right)^{\mathrm{e}}\end{array}$ & $\frac{V_{p}}{\left(\mathrm{~cm}^{3} \cdot \mathrm{g}^{-1}\right)^{\mathrm{e}}}$ & $D_{p}(n m) e$ \\
\hline $\mathrm{TiO}_{2}$ & $\begin{array}{c}100 \% \\
\text { Anatase }\end{array}$ & 61.4 & 132.9 & 3.91 & 16.6 & 11.6 & 0.02 & 7.9 \\
\hline $\mathrm{N} / \mathrm{Ag} / \mathrm{TiO}_{2}$ & $\begin{array}{c}100 \% \\
\text { Anatase }\end{array}$ & 11.4 & 61.8 & 4.25 & 38.1 & 101.3 & 0.26 & 15.9 \\
\hline
\end{tabular}

${ }^{a}$ Crystallite size calculated from the X-ray diffraction (XRD) peak at $2 \theta$ of $25^{\circ}$ (101) using Debye-Scherrer's Equation. ${ }^{\mathrm{b}}$ Average agglomerate crystallite size calculated using scanning electron microscopy $(\mathrm{SEM}) .{ }^{\mathrm{c}}$ Unit cell density $\left(\rho_{\mathrm{p}}\right)$ calculated from the mass per unit cell over its cell volume [23,24]. ${ }^{\mathrm{d}}$ Agglomerate particle density $=\rho_{\text {crystallite }}(1-\varepsilon)$, with $\varepsilon$ being 0.5 for bare- $\mathrm{TiO}_{2}$ and 0.6 for $\mathrm{N} / \mathrm{Ag} / \mathrm{TiO}{ }_{2}$ [25]. ${ }^{\mathrm{e}} \mathrm{Specific}$ surface area $\left(\mathrm{S}_{\mathrm{BET}}\right)$, pore volume $\left(\mathrm{V}_{\mathrm{p}}\right)$ and pore diameter $\left(\mathrm{D}_{\mathrm{p}}\right)$, determined by $\mathrm{N}_{2}$ adsorption-desorption, using the Brunauer-Emmett-Teller (BET) and Barrett-Joyner-Halenda (BJH) methods, respectively.

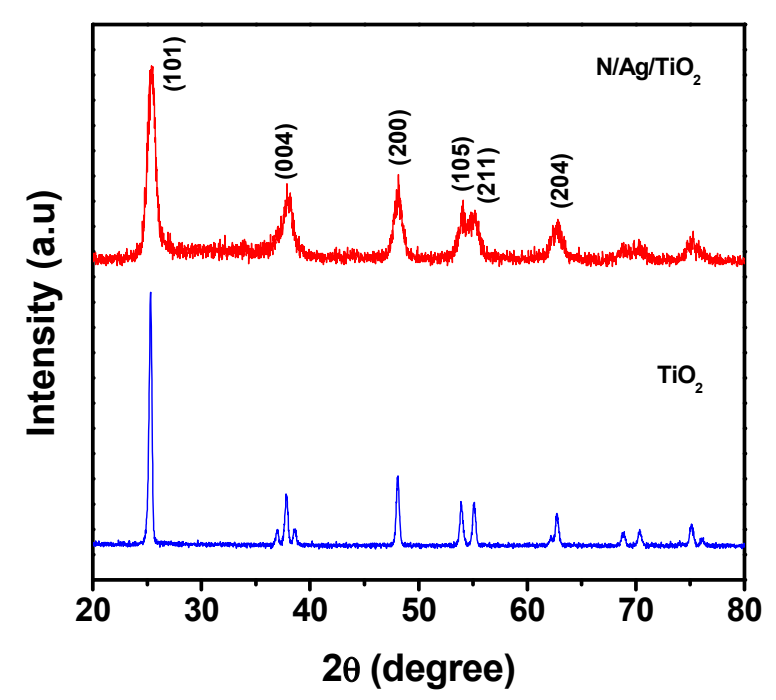

(a)

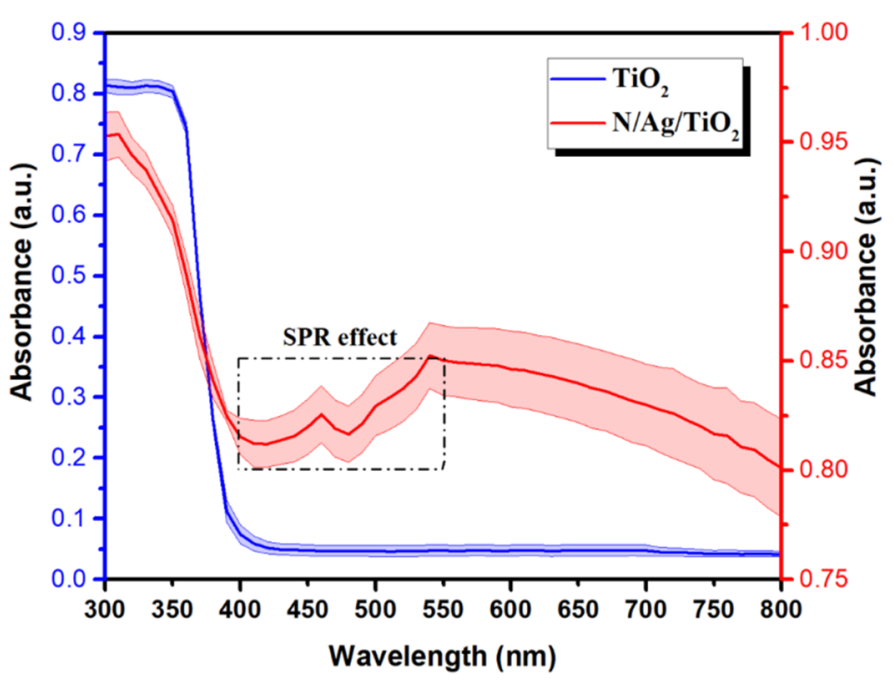

(b)

Figure 1. (a) XRD spectra, and (b) ultraviolet-visible (UV-vis) Absorption of the $\mathrm{N} / \mathrm{Ag} / \mathrm{TiO}_{2}$ Compared to that of the bare- $\mathrm{TiO}_{2}$.

Figure $1 \mathrm{~b}$ displays the ultraviolet-visible (UV-vis) absorbance spectra for a $\mathrm{N} / \mathrm{Ag} / \mathrm{TiO}_{2}$ and a bare- $\mathrm{TiO}_{2}$. It was observed that there was a significant change on the typical bare- $\mathrm{TiO}_{2}$ absorbance variation with wavelength as follows (a) absorbance decreased as expected, in the $300-400 \mathrm{~nm}$ range, (b) absorbance augmented in 400 to $550 \mathrm{~nm}$ range. This modification was attributed to the surface plasmon resonance (SPR) effect of Ag nanoparticles [38-43] which was confirmed via photoluminescence (PL), as documented in the Supplementary Materials (Figure S5) and by Sirivallop et al. [13]. Thus, it can be anticipated that photoexcited electrons and holes in the $\mathrm{N} / \mathrm{Ag} / \mathrm{TiO}_{2}$ can be separated when using visible light more efficiently [44]. Another factor contributing to the anticipated visible light enhanced photoactivity was assigned to reduced band gaps for the $\mathrm{N} / \mathrm{Ag} / \mathrm{TiO}_{2}$ as documented by others [13]. 
The photocatalyst surface acidity is also an important parameter for photocatalytic activity. This was determined by using the ammonia temperature-programmed desorption (TPD) under standard temperature and pressure (STP) conditions. Figure 2 reports the $\mathrm{NH}_{3}$-TPD profiles of both bare- $\mathrm{TiO}_{2}$ and $\mathrm{N} / \mathrm{Ag} / \mathrm{TiO}_{2}$ photocatalysts. Table 2 reports the amounts of $\mathrm{NH}_{3}$ desorbed from the studied photocatalyst, obtained by the integration of TPD profiles. One can see that $\mathrm{N} / \mathrm{Ag} / \mathrm{TiO}_{2}$ exhibited the higher peak intensity and higher total amount of $\mathrm{NH}_{3}$ desorbed per unit mass, as compared to the bare- $\mathrm{TiO}_{2}$. However as shown in Table 1, and once the desorbed amount of $\mathrm{NH}_{3}$ based on the unit area of semiconductor is considered, one can see that the bare- $\mathrm{TiO}_{2}$ displays larger ammonia desorbed values than the $\mathrm{N} / \mathrm{Ag} / \mathrm{TiO}_{2}$. This clearly indicates that the overall $\mathrm{N} / \mathrm{Ag} / \mathrm{TiO}_{2}$ acidity density per unit surface area is significantly reduced due to the $\mathrm{N}$ and $\mathrm{Ag}$ addition.

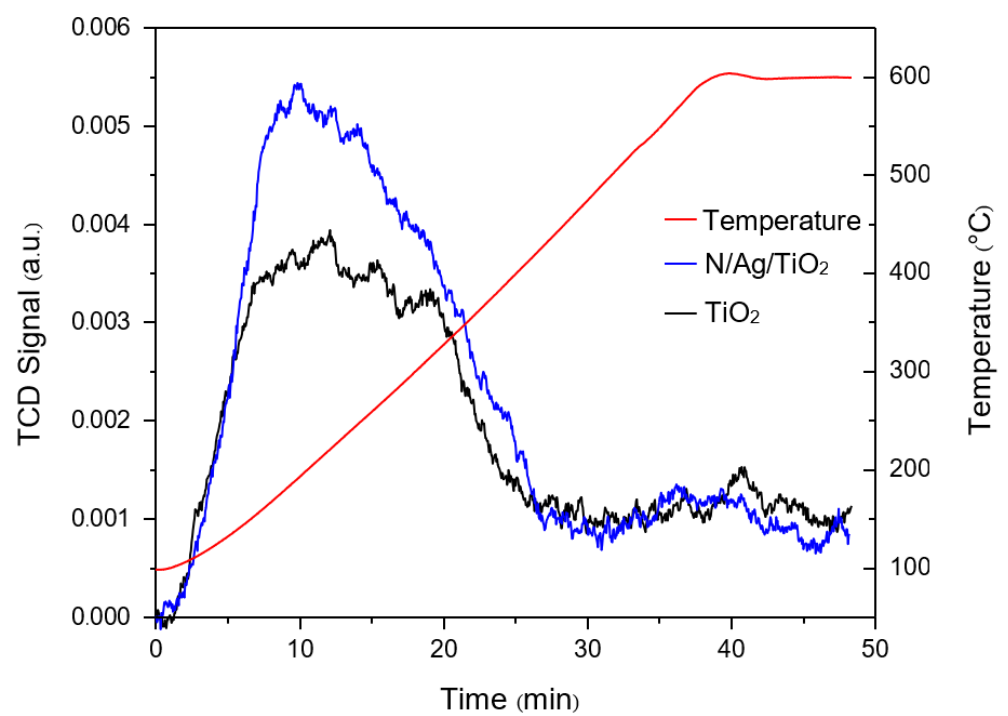

Figure 2. $\mathrm{NH}_{3}$-temperature-programmed desorption (TPD) profiles of the synthesized bare- $\mathrm{TiO}_{2}$ and the $\mathrm{N} / \mathrm{Ag} / \mathrm{TiO}_{2}$ photocatalysts.

Table 2. $\mathrm{NH}_{3}-\mathrm{TPD}$ characterization of the synthesized bare- $\mathrm{TiO}_{2}$ and $\mathrm{N} / \mathrm{Ag} / \mathrm{TiO}_{2}$ photocatalysts.

\begin{tabular}{cccc}
\hline Catalyst & $\begin{array}{c}\text { Volumetric Change } \\
\left(\mathbf{c m}^{\mathbf{3}} \cdot \mathbf{m i n}^{-\mathbf{1}} \mathbf{)} \mathbf{( S T P )}\right.\end{array}$ & $\begin{array}{c}\mathbf{N H}_{\mathbf{3}} \text { Uptake } \\
\left(\mathbf{c m}^{\mathbf{3}} \cdot \mathbf{g}^{-\mathbf{1}} \mathbf{)} \mathbf{( S T P )}\right.\end{array}$ & $\begin{array}{c}\mathbf{N H}_{\mathbf{3}} \text { Uptake } \\
\mathbf{c m}^{\mathbf{3}} / \mathbf{m}^{\mathbf{2}}\end{array}$ \\
\hline $\mathrm{Bare}-\mathrm{TiO}_{2}$ & $0.043 \pm 0.002$ & $7.1 \pm 0.3$ & 0.61 \\
$\mathrm{~N} / \mathrm{Ag} / \mathrm{TiO}_{2}$ & $0.064 \pm 0.003$ & $10.8 \pm 0.5$ & 0.11 \\
\hline
\end{tabular}

Furthermore, an X-ray photoelectron spectroscopy (XPS) analysis was performed to determine the semiconductor surface composition and to understand how the $\mathrm{N}$ and $\mathrm{Ag}$ dopants interact with the bare- $\mathrm{TiO}_{2}$ lattice. Additional XPS information regarding the photocatalyst of the present study is given in Sirivallop et al. [13]. The surface compositions and chemical states of the prepared photocatalysts of bare- $\mathrm{TiO}_{2}$ and $\mathrm{N} / \mathrm{Ag} / \mathrm{TiO}_{2}$ are summarized in Table 3. Figure 3a shows the survey XPS spectra of both the $\mathrm{N} / \mathrm{Ag} / \mathrm{TiO}_{2}$ and the bare- $\mathrm{TiO}_{2}$. One can notice that the characteristic peaks of $\mathrm{Ti} 2 \mathrm{p}$ and $\mathrm{O} 1 \mathrm{~s}$, located at the binding energies (BE) of around $458-465 \mathrm{eV}$ and $530 \mathrm{eV}$, respectively, were observed in both the bare- $\mathrm{TiO}_{2}$ and the $\mathrm{N} / \mathrm{Ag} / \mathrm{TiO}_{2}$ sample. This was attributed to the Ti-O-Ti bonds in the bare- $\mathrm{TiO}_{2}$. However, the additional peaks of the nitrogen atom as well those of the silver atom were only observed in the $\mathrm{N} / \mathrm{Ag} / \mathrm{TiO}_{2}$ sample, at about $400 \mathrm{eV}$ and $370 \mathrm{eV}$ for $\mathrm{N} 1 \mathrm{~s}$ and $\mathrm{Ag} 3 \mathrm{~d}$, respectively. The XPS shows the $284.6 \mathrm{eV} \mathrm{C} 1$ s the carbon atom reference peak as well. 
Table 3. Surface compositions (in at. \%) of bare- $\mathrm{TiO}_{2}$ and $\mathrm{N} / \mathrm{Ag} / \mathrm{TiO}_{2}$ photocatalysts, obtained by XPS.

\begin{tabular}{|c|c|c|c|c|c|c|c|c|c|c|}
\hline \multirow[b]{3}{*}{ Samples } & \multicolumn{2}{|c|}{ Ti Content } & \multicolumn{2}{|c|}{ O Content } & \multicolumn{3}{|c|}{ N Content } & \multicolumn{3}{|c|}{ Ag Content } \\
\hline & \multicolumn{10}{|c|}{ (at. \%) } \\
\hline & $\mathrm{Ti}^{4+}$ & $\mathrm{Ti}^{3+}$ & $\begin{array}{c}\text { Ti-OH } \\
(531.9 \mathrm{eV})\end{array}$ & $\begin{array}{c}\text { Ti-O-Ti } \\
(530.8 \mathrm{eV})\end{array}$ & $\begin{array}{c}\mathrm{N}-\mathrm{O} \\
(401.1 \mathrm{eV})\end{array}$ & $\begin{array}{c}\text { N-Ti-O } \\
(399.7 \mathrm{eV})\end{array}$ & $\begin{array}{c}\text { Ti-N-O } \\
(398.1 \mathrm{eV})\end{array}$ & $\begin{array}{c}\mathrm{Ag}(0) \\
(369.8 \mathrm{eV})\end{array}$ & $\begin{array}{c}\mathrm{Ag}_{2} \mathrm{O} \\
(368.4 \mathrm{eV})\end{array}$ & $\begin{array}{c}\mathrm{AgO} \\
(367.8 \mathrm{eV})\end{array}$ \\
\hline Bare-TiO ${ }_{2}$ & 94.24 & 5.76 & 20.09 & 79.91 & - & - & - & - & - & - \\
\hline $\mathrm{N} / \mathrm{Ag} / \mathrm{TiO}_{2}$ & 86.41 & 13.59 & 11.0 & 89.0 & 29.04 & 36.99 & 33.97 & 5.36 & 83.93 & 10.71 \\
\hline
\end{tabular}

(a)

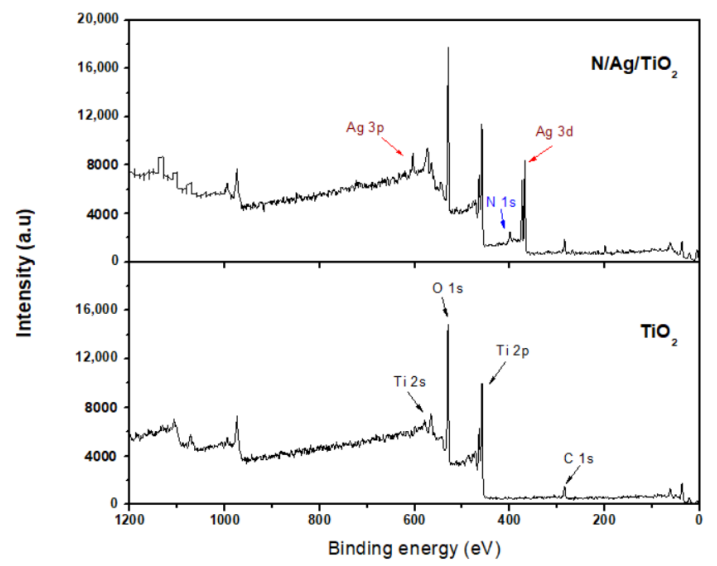

(c)

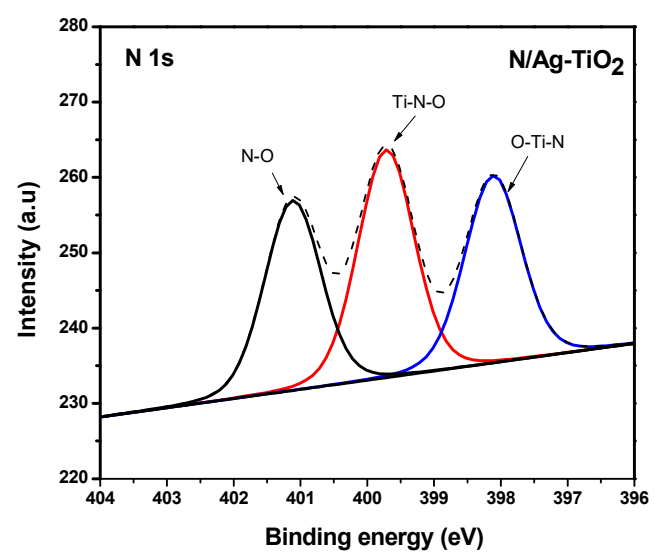

(b)

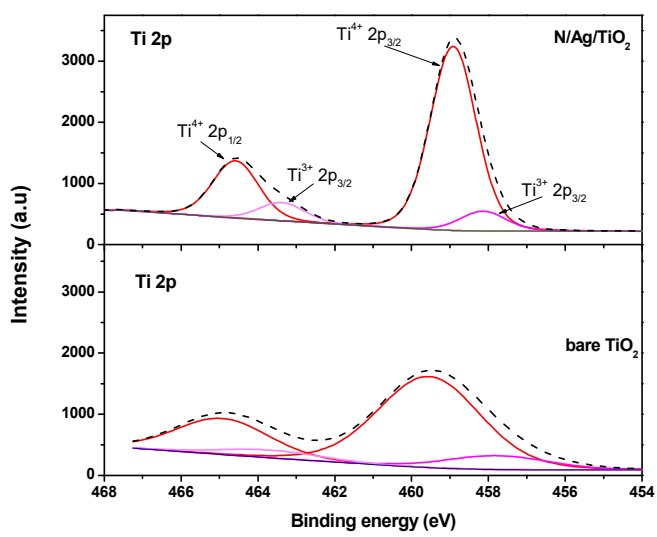

(d)

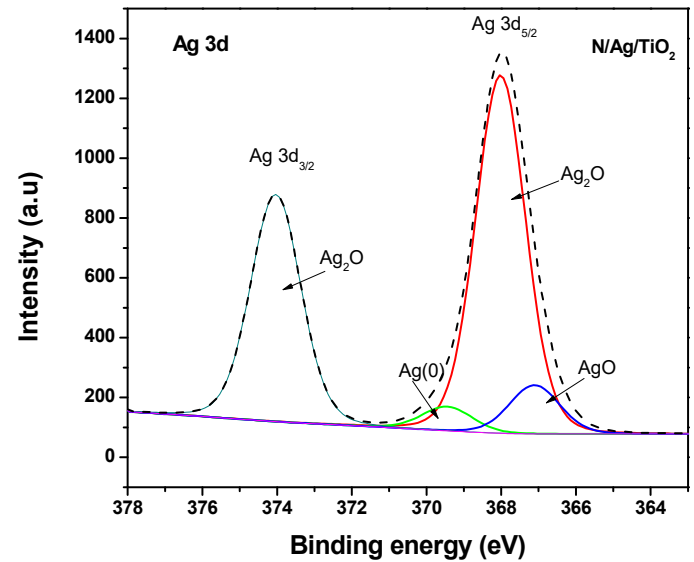

Figure 3. (a) Full X-ray photoelectron spectroscopy (XPS) spectra of $\mathrm{N} / \mathrm{Ag} / \mathrm{TiO}_{2}$ and bare- $\mathrm{TiO}_{2}$ photocatalysts and highresolution spectra of (b) Ti 2p, (c) N 1s, and (d) Ag 3d.

By considering the Ti state from the XPS high-resolution spectra as shown in Figure $3 \mathrm{~b}$, the intensive peak of Ti $2 p_{3 / 2}$, at a binding energy of $458.5 \mathrm{eV}$ (>90 at.\%), corresponding to the $\mathrm{Ti}^{4+}$ in the bare- $\mathrm{TiO}_{2}$ lattice, was observed. This was the case agreement with $[45,46]$ for both the bare- $\mathrm{TiO}_{2}$ and $\mathrm{N} / \mathrm{Ag} / \mathrm{TiO}_{2}$ photocatalysts. Also, a small $\mathrm{Ti}_{2} \mathrm{O}_{3}$ amount $(<10$ at.\%), corresponding to the oxygen vacancies was also observed. One should note that the Ti $2 p$ bands for the $\mathrm{N} / \mathrm{Ag} / \mathrm{TiO}_{2}$ shifted slightly to the lower binding energies. This was attributed to the change in electronic interaction between bare- $\mathrm{TiO}_{2}$ and silver [47].

Figure 3c shows the high-resolution XPS spectra for N1s, located in the 399-401.1 eV binding energy (BE) range. This suggests that the incorporation of an $\mathrm{N}$ atom into the bare- $\mathrm{TiO}_{2}$ crystal lattice was achieved by the bonding of three different species. The XPS spectra bands at $398.1 \mathrm{eV}$ and $399.7 \mathrm{eV}$ correspond to interstitial $\mathrm{N}$ doping (33.97 at.\%) and substitutional $\mathrm{N}$ doping (36.99 at.\%), respectively [48]. The higher BE of $401.1 \mathrm{eV}$ (29.04 at.\%) is usually ascribed to a chemisorbed nitrogen [49]. The most intensive peaks of the substitutional $\mathrm{N}$, which occur by replacing the $\mathrm{O}$ atom by an $\mathrm{N}$ atom, in the bare- $\mathrm{TiO}_{2}$ lattice in order to form $\mathrm{O}-\mathrm{Ti}-\mathrm{N}$ linkages, as well as the interstitial $\mathrm{N}$ are much more effective in the bare- $\mathrm{TiO}_{2}$ crystal lattice [45-50]. 
These various findings are in good agreement with the XRD results. They are also in good accordance with Pisarek et al., who reported that the bare- $\mathrm{TiO}_{2}$ crystal lattice structural changes occur through the incorporation of $\mathrm{N}$ into it, by forming of a Ti-N-O bond (396.7-397.1 eV) and a N-Ti-O bond (398.0-399.0 eV) [51]. Xu et al. also reported that the crystal structure and lattice parameters of bare- $\mathrm{TiO}_{2}$ are affected by $\mathrm{N}$ doping. The substitution of $\mathrm{N}$ into bare- $\mathrm{TiO}_{2}$ crystal lattice by replacing for $\mathrm{O}$ atom can also be confirmed by the change in surface electron densities of each elements in N-Ti-O linkage. Due to the electronegativity of the $\mathrm{O}$ atom (3.5) is greater than that of the $\mathrm{N}$ atom (3.0), it affects electron transfers from the $\mathrm{N}$ atom to the Ti atom. This leads to a reduction in electron density on the $\mathrm{N}$ atom, and subsequently increases the electron density on the Ti atom [24]. The BE peak at about $399.9 \mathrm{eV}$ is possibly related to a reduction of nitrogen electron density due to the high electronegativity of oxygen, as reported by others [50-52]. Consequently, this further proves that $\mathrm{N}$ was incorporated into the lattice and substituted for oxygen.

Figure $3 \mathrm{~d}$ depicts the XPS spectra for Ag $3 \mathrm{~d}$ with two major peaks of $\mathrm{Ag} 3 \mathrm{~d}_{3 / 2}$ and $\mathrm{Ag} 3 \mathrm{~d}_{5 / 2}$, located at $373.60 \mathrm{eV}$ and $367.6 \mathrm{eV}$, respectively. Considering the signal peak of $\mathrm{Ag} 3 \mathrm{~d}_{5 / 2}$, it was noticed that the introduction of silver in the lattice surface of the bare$\mathrm{TiO}_{2}$ provides three different silver states: $\mathrm{Ag}^{0}$ (5.36 at.\%), $\mathrm{Ag}_{2} \mathrm{O}$ (83.93 at.\%) and $\mathrm{AgO}$ (10.71 at.\%) located at $369.8 \mathrm{eV}, 368.4 \mathrm{eV}$ and $367.8 \mathrm{eV}$, respectively [47]. This showed that the content of oxidized silver in the bare- $\mathrm{TiO}_{2}$ is larger than the content of metallic silver $\left(\mathrm{Ag}^{0}\right)$, with both $\mathrm{Ag}^{0}$ and $\mathrm{Ag}^{+}$in the bare- $\mathrm{TiO}_{2}$ crystal lattice, playing a critical role in the electron-hole separation and as a result, the photocatalytic performance [53,54]. According to Santos et al. (2015), $\mathrm{Ag}^{0}$ clusters could allow strong visible light absorption on the $\mathrm{TiO}_{2}$ surface [55]. This is due to their surface plasmon resonance (SPR) effect. Furthermore, Batalović et al. (2017) have mentioned that a metal atom deposited on a $\mathrm{TiO}_{2}$ surface could create a catalytically active surface, for reaction intermediates [45].

In this respect, as seen in previous studies, and another paper by Sirivallop et al. [13], the $\mathrm{N}$ and $\mathrm{Ag}$ addition in bare- $\mathrm{TiO}_{2}$ was responsible for several positive effects on the physicochemical properties such as: (a) smaller anatase crystallites, (b) higher surface area, (c) surface plasmon resonance (SPR) for silver, (d) narrow bandgap energy and (e) high charge separation efficiency. One should note, however, that the increased of external agglomerate specific surface as well as the reduced acidity based on the unit surface area, was observed in the case of the $\mathrm{N} / \mathrm{Ag} / \mathrm{TiO}_{2}$ crystal lattice. This combination of semiconductor properties allows one to explain the methanol photocatalytic degradation under visible and near-UV irradiation.

\subsection{Photon Absorption Efficiency}

The measurements of incident radiation, transmitted light and backscattered light by the photocatalyst were taken at various axial and angular positions, in order to obtain the total photon absorption by the photocatalyst. Table 4 reports the total photon absorption calculated, based on the macroscopic radiation balances of the bare- $\mathrm{TiO}_{2}$ and of the $\mathrm{N} / \mathrm{Ag} / \mathrm{TiO}_{2}$-coated photocatalyst on the cylindrical stainless-steel woven mesh (2 wt.\% loadings), under either near-UV or visible light illumination. The total photons transmitted and backscattered by the photocatalyst were also determined by showing that the incident light was not only absorbed by the photocatalyst but could also be transmitted and backscattered from the mesh surface.

Figure 4 reports the photon absorption efficiency of near-UV light and visible light irradiation calculated from the ratio of absorbed photons by the photocatalyst over the irradiated photons reaching the photocatalyst surface. 
Table 4. Calculated photon fluxes of incident light $\left(\mathrm{P}_{\mathrm{i}}, \mathrm{r}=5.9 \mathrm{~cm}\right)$, transmitted light $\left(\mathrm{P}_{\mathrm{t}}, 5.25 \mathrm{~cm}\right)$ and backscattered light $\left(\mathrm{P}_{\mathrm{bs}}, \mathrm{r}=7.7\right)$ by the coated mesh. All occur when using the woven mesh coated with $2 \mathrm{wt}$.\% of photocatalyst loading under either near-UV (320-380 nm wavelength) or visible light (380-700 nm wavelength).

\begin{tabular}{|c|c|c|c|c|}
\hline $\begin{array}{l}\text { Light Source/ } \\
\text { Photocatalyst }\end{array}$ & $P_{i}\left(\right.$ Photon s $\left.{ }^{-1}\right)$ & $P_{t}\left(\right.$ Photon $\left.^{-1}\right)$ & $P_{b s}\left(\right.$ Photon s $\left.{ }^{-1}\right)$ & $P_{a}\left(\right.$ Photon $\left.\mathrm{s}^{-1}\right)$ \\
\hline $\begin{array}{c}\text { Bare- } \mathrm{TiO}_{2} \\
\mathrm{~N} / \mathrm{Ag} / \mathrm{TiO}_{2}\end{array}$ & $5.06 \times 10^{18}$ & $\begin{array}{l}\text { Near-UV light } \\
9.91 \times 10^{16} \\
1.45 \times 10^{17} \\
\text { Visible light }\end{array}$ & $\begin{array}{l}7.78 \times 10^{17} \\
4.60 \times 10^{17}\end{array}$ & $\begin{array}{l}4.18 \times 10^{18} \\
4.46 \times 10^{18}\end{array}$ \\
\hline $\begin{array}{c}\text { Bare- }-\mathrm{TiO}_{2} \\
\mathrm{~N} / \mathrm{Ag} / \mathrm{TiO}_{2}\end{array}$ & $4.85 \times 10^{18}$ & $\begin{array}{l}2.50 \times 10^{18} \\
8.80 \times 10^{17}\end{array}$ & $\begin{array}{l}8.00 \times 10^{17} \\
1.65 \times 10^{16}\end{array}$ & $\begin{array}{l}1.55 \times 10^{18} \\
3.95 \times 10^{18}\end{array}$ \\
\hline
\end{tabular}

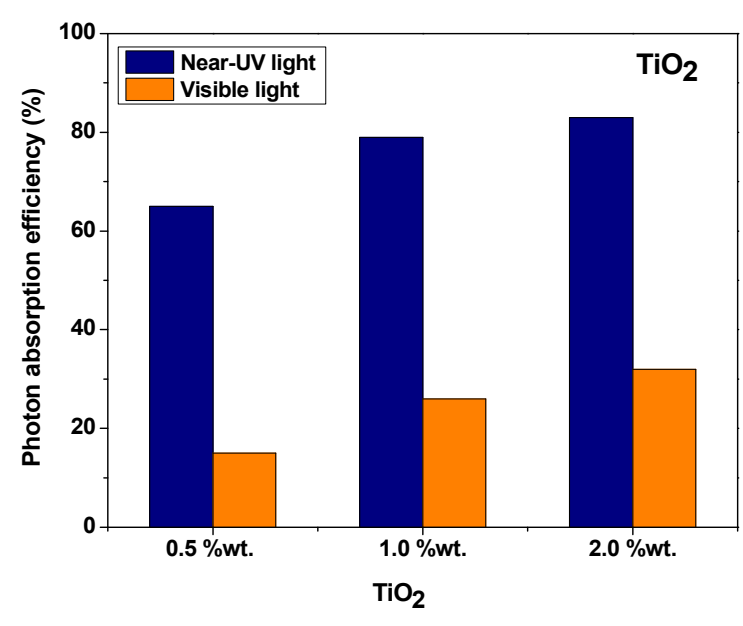

(a)

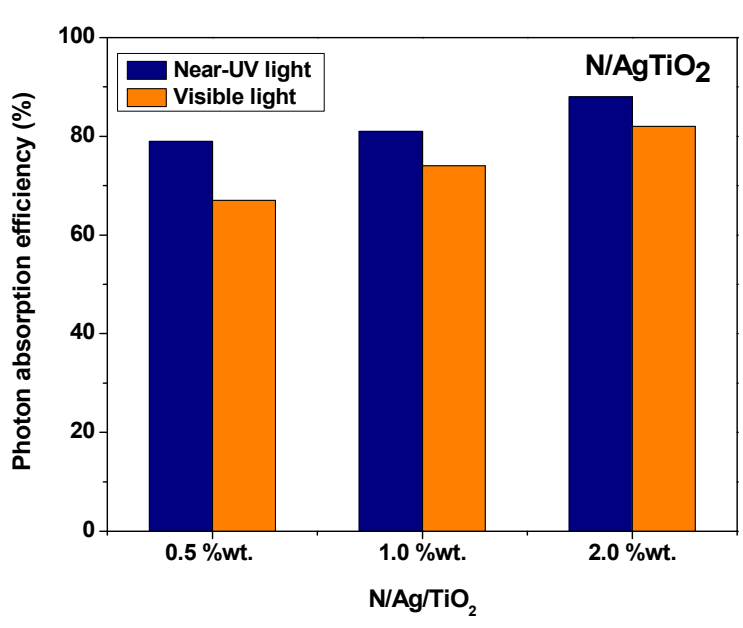

(b)

Figure 4. Near-UV light and visible light radiation photon absorption efficiencies on: (a) bare- $\mathrm{TiO}_{2}$, and (b) $\mathrm{N} / \mathrm{Ag} / \mathrm{TiO}$. Both bare- $\mathrm{TiO}_{2}$ and $\mathrm{N} / \mathrm{Ag} / \mathrm{TiO}_{2}$ are coated on the cylindrical stainless-steel woven mesh at different particle loadings (0.5-2 wt.\%).

In this respect, one can see in Figure 4 that the $\mathrm{N} / \mathrm{Ag} / \mathrm{TiO}_{2}$ exhibits higher photon absorption efficiencies both under near-UV (80-90\%) as well as visible light (70-80\%). On the other hand, the bare- $\mathrm{TiO}_{2}$ showed a $65-80 \%$ photon absorption efficiency under near-UV irradiation, with a poor absorption capacity (less than $30 \%$ ) under the visible light radiation. Furthermore, it was also noticed in Figure $4 \mathrm{~b}$ (using the $\mathrm{N} / \mathrm{Ag} / \mathrm{TiO}_{2}$ ), that the photon absorption efficiency increased with the amount of photocatalyst loading on the stainless-steel woven mesh, with $2 \mathrm{wt} . \%$ providing the highest photon absorption. Given this demonstrated higher photon absorption, these results anticipate that the $\mathrm{N} / \mathrm{Ag} / \mathrm{TiO}_{2}$ photocatalyst holds special promise, for the photocatalytic degradation of VOCs under visible light.

\subsection{Photocatalytic Conversion of Methanol}

3.3.1. Photocatalytic Methanol Conversion by bare- $\mathrm{TiO}_{2}$ and $\mathrm{N} / \mathrm{Ag} / \mathrm{TiO}_{2}$ under Near-UV and Visible Light Irradiation

The photocatalytic oxidation of gas phase methanol in a recirculating batch PhotoCREC-Air Reactor was carried out under two different light source illuminations: near-UV and visible light, by using either bare- $\mathrm{TiO}_{2}$ or $\mathrm{N} / \mathrm{Ag} / \mathrm{TiO}_{2}$ coated on a stainless-steel woven mesh. Various chemical species formed were determined by using a gas chromatograph unit with a flame ionization detector (GC-FID). Supplementary Materials A and B reports a typical GC-FID chromatogram and calibration curves for various photocatalytic methanol conversion products. This chromatogram showed conclusively that there are no other 
chemical species detected under dark conditions, except the injected methanol and the $\mathrm{CO}_{2}$ contained in the atmosphere at a constant concentration.

Figure $5 \mathrm{a}, \mathrm{b}$ report the photocatalytic conversion of methanol and the formation of formaldehyde and formic acid intermediates, when using the bare- $\mathrm{TiO}_{2}$ under near-UV and visible light, respectively. The coated bare- $\mathrm{TiO}_{2}$ in Figure 5 a shows an excellent photocatalytic activity under the near-UV light irradiation, with rapid methanol degradation and essentially zero methanol concentration achieved in $110 \mathrm{~min}$ of irradiation time. One can also notice that the intermediate species formaldehyde and formic species are formed in small amounts, disappearing later when $\mathrm{CO}_{2}$ reaches its maximum level. Regarding the chemical species detected, one can observe that the concentration of these chemical species always provides a carbon balance closure, near $100 \%$, allowing one to conclude that there is a modest influence of adsorbed hydrocarbon species during the run. One can also see in Figure $5 b$, and in contrast with the results in Figure $5 a$, that the bare- $\mathrm{TiO}_{2}$ photocatalyst becomes essentially inactive under the visible light, with methanol concentration hardly decreasing with irradiation time. One should note that the close to $100 \%$ carbon balance shows the reliable accounting of all carbon containing species during the experiments.

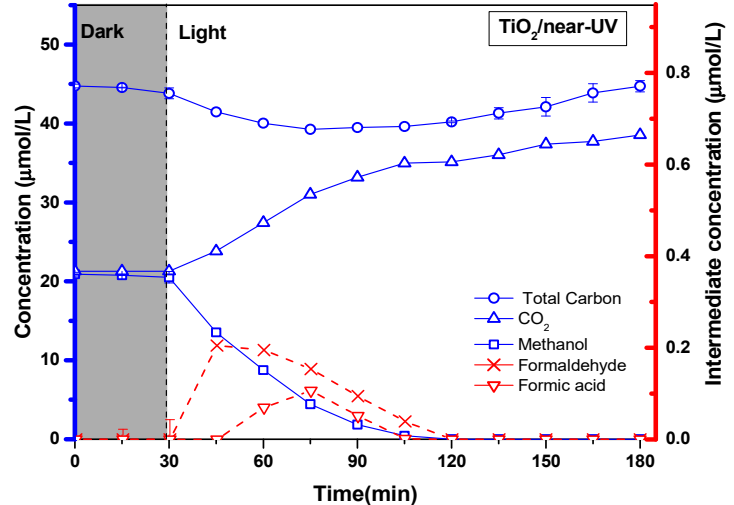

(a) Bare- $\mathrm{TiO}_{2}$ near-UV

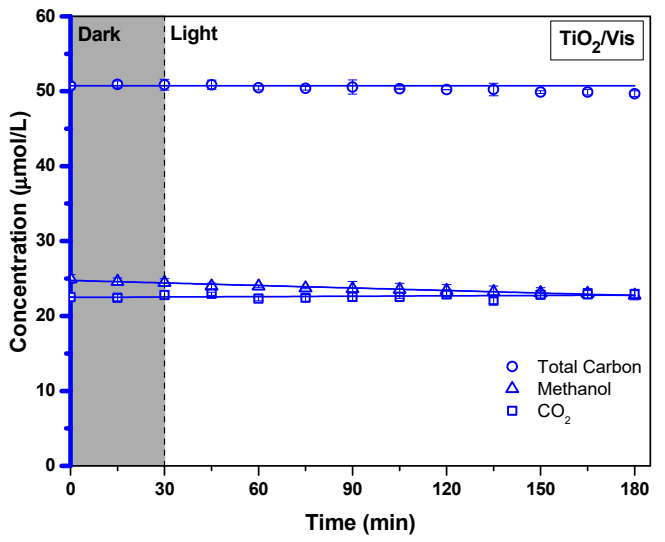

(b) Bare- $\mathrm{TiO}_{2}$ visible light

Figure 5. Photocatalytic conversion of $21 \mu \mathrm{mol} / \mathrm{L}$ of methanol on $0.5 \mathrm{wt}$. $\%$ bare- $-\mathrm{TiO}_{2}$ coated on a stainless-steel woven mesh as well as, under (a) near-UV and (b) visible light. Note1: (i) the left $Y$ blue coordinate refers to the concentration of methanol $(\square), \mathrm{CO}_{2}(\Delta)$ as well as total carbon $(\circ)$, and the right $Y$ red coordinate refers to intermediates concentration of formaldehyde $(\times)$ and formic acid $(\nabla)$ species; in addition to, (ii) Mean values corresponding to at least 3 repeats with a standard deviation (SD) of $10 \pm 3 \%$. Note2: The close to $100 \%$ total carbon balance shows the reliable accounting of all carbon-containing species during the runs.

Figure $6 \mathrm{a}, \mathrm{b}$ report the photocatalytic conversions of methanol under near-UV and visible light, using the $\mathrm{N} / \mathrm{Ag} / \mathrm{TiO}_{2}$ photocatalyst, which displays good photodegradation in both cases. Figure $6 \mathrm{a}, \mathrm{b}$ also show that both formaldehyde and formic acid are two produced intermediate species in both cases, while concentrations are reduced with irradiation time. Note 2: One should note that close to $100 \%$ total carbon, calculated as a summation of all carbon-containing species at any time during the run, shows the reliable accounting of all chemical species.

Results obtained during the developed runs, as shown in Figure 6a,b, can be explained as follows: (a) there is essentially no detectable photocatalytic activity for the bare- $\mathrm{TiO}_{2}$ and (b) there is significant photocatalytic activity when using $\mathrm{N} / \mathrm{Ag} / \mathrm{TiO}_{2}$ photocatalysts. Differences in photoactivity can be assigned to the reduction of the optical band gap, and the enhanced photon absorption capacity of the $\mathrm{N} / \mathrm{Ag} / \mathrm{TiO}_{2}[45,55]$.

From the above experimental results, a series-parallel reaction pathway for the photocatalytic conversion of gas-phase methanol to $\mathrm{CO}_{2}$, in a Photo-CREC-Air Reactor, can be considered, as described in Figure 7. 


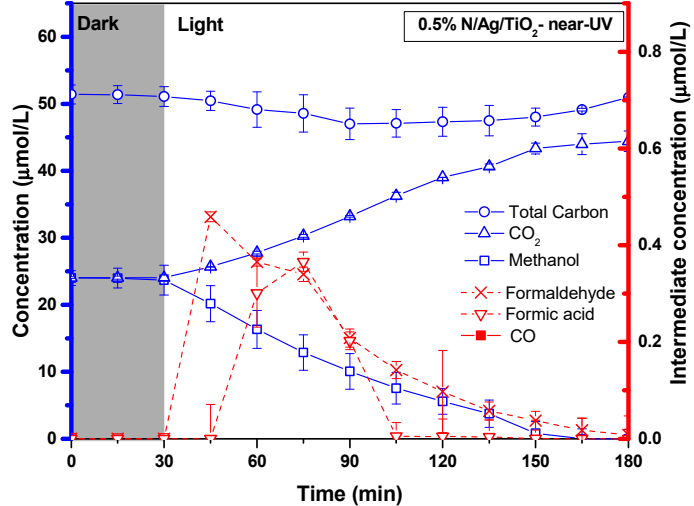

(a) $\mathrm{N} / \mathrm{Ag} / \mathrm{TiO}_{2}-\mathrm{Near}-\mathrm{UV}$

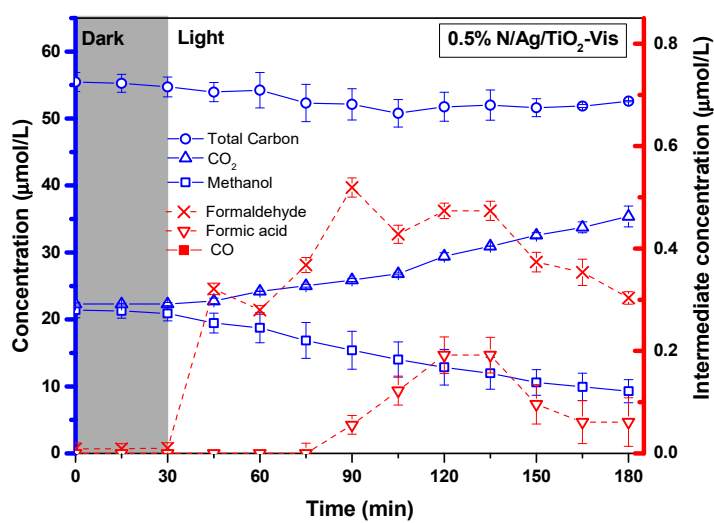

(b) $\mathrm{N} / \mathrm{Ag} / \mathrm{TiO}_{2}-\mathrm{Visible}$

Figure 6. Photocatalytic conversion of $25 \mu \mathrm{mol} / \mathrm{L}$ of methanol on a $0.5 \mathrm{wt} . \% \mathrm{~N} / \mathrm{Ag} / \mathrm{TiO}_{2}$ coated on a stainless-steel woven mesh as well as, under (a) near-UV and (b) visible light. Note 1: (i) the left $\mathrm{Y}$ blue coordinate refers to the concentration of methanol $(\square), \mathrm{CO}_{2}(\Delta)$ as well as total carbon $(\circ)$, and the right $Y$ red coordinate refers to intermediates concentration of formaldehyde $(\times)$ and formic acid $(\nabla)$ species; in addition to, (ii) mean values corresponding to at least 3 repeats with a standard deviation (SD) of $15 \pm 5 \%$. Note 2 : The close to $100 \%$ total carbon shows the reliable accounting of all carbon containing species during the runs.

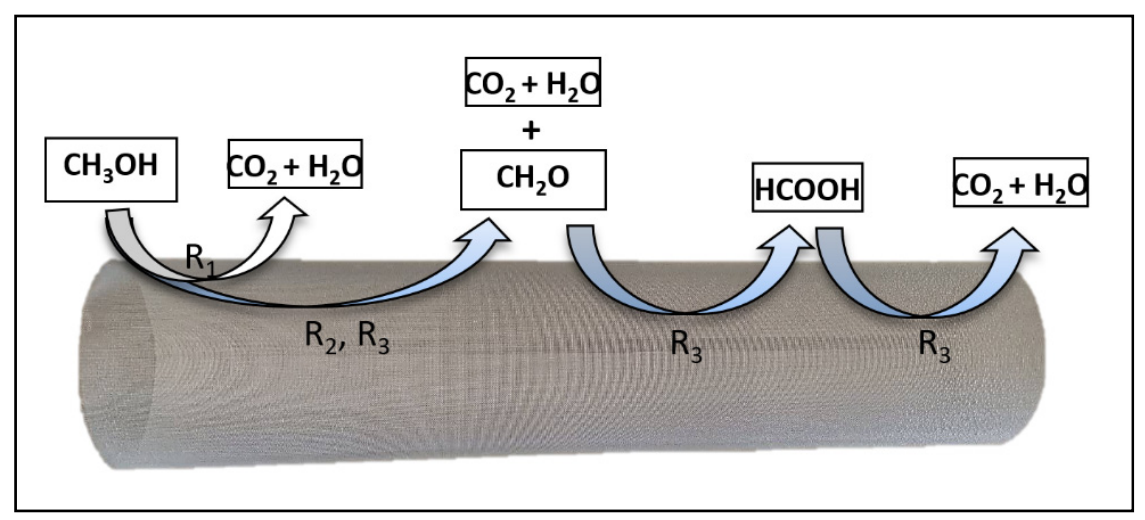

Figure 7. Series-parallel reaction pathways for methanol photoconversion into $\mathrm{CO}_{2}$, on the bare- $\mathrm{TiO}_{2}$ and the $\mathrm{N} / \mathrm{Ag} / \mathrm{TiO}_{2-}$, Immobilized on a mesh in a photo-CREC-Air Reactor.

This series-parallel network accounts for the following steps: (i) a first reaction step $\left(\mathrm{R}_{1}\right)$, with methanol oxidizing to $\mathrm{CO}_{2}$ directly, without any detectable reaction intermediates, (ii) a second reaction step $\left(\mathrm{R}_{2}\right)$ with methanol oxidizing to $\mathrm{CO}_{2}$, yielding formaldehyde $\left(\mathrm{CH}_{2} \mathrm{O}\right)$ as a detectable intermediate, and decomposing later into $\mathrm{CO}_{2}$, and (iii) a third reaction step $\left(\mathrm{R}_{3}\right)$, accounting for methanol oxidizing to $\mathrm{CO}_{2}$, with formaldehyde $\left(\mathrm{CH}_{2} \mathrm{O}\right)$ and formic acid $(\mathrm{HCOOH})$ as intermediate species.

The series-parallel network mechanism can be considered on the basis of (a) methanol concentration decreasing progressively, with $\mathrm{CO}_{2}$ continuously increasing with irradiation time, (b) a $\mathrm{CO}_{2}$ formation rate of non-zero at early irradiation times and (c) formaldehyde and formic acid displaying maximum values at about similar irradiation times.

This photocatalytic pathway for methanol oxidation photoconversion is in agreement with Lv et al. [56], Lugo-Vega et al. [15], and de Lasa et al. [19]. de Lasa et al. (2005) introduced the "series-parallel" network scheme, validating it based on the expected and unavoidable differences in photon density at various photocatalytic reactor locations.

\subsubsection{Effect of Photocatalyst Loading}

The photocatalytic degradation of methanol was evaluated at a relative humidity of $35-46 \%$ range (refer to Appendix B), varying the percentage weight of the immobilized 
photocatalyst on the cylindrical stainless-steel woven mesh as follows: $0.5 \mathrm{wt} . \%, 1 \mathrm{wt} . \%$ and 2 wt.\%

Figure $8 \mathrm{a}, \mathrm{b}$ report the photocatalytic activity of methanol degradation using different loadings of bare- $-\mathrm{TiO}_{2}$ and $\mathrm{N} / \mathrm{Ag} / \mathrm{TiO}_{2}$ immobilized on the mesh, respectively. From these figures, one can notice that the activity of photocatalytic methanol degradation under near-UV light depends on the amount of photocatalyst loaded. Consistent with this, higher amounts ( $2 \mathrm{wt} . \%$ ) of either bare- $\mathrm{TiO}_{2}$ or $\mathrm{N} / \mathrm{Ag} / \mathrm{TiO}_{2}$ showed greater methanol degradation rates as compared to lower photocatalyst loadings. For bare- $\mathrm{TiO}_{2}$, the fastest photocatalytic reaction for methanol degradation was observed when using a mesh coated with 2 wt.\% of bare- $\mathrm{TiO}_{2}$. This showed a complete methanol degradation within 90 min of near-UV irradiation: $k=2.2 \times 10^{-2} \mathrm{~min}^{-1}\left(R^{2}=0.98\right)$ (see Table 5).

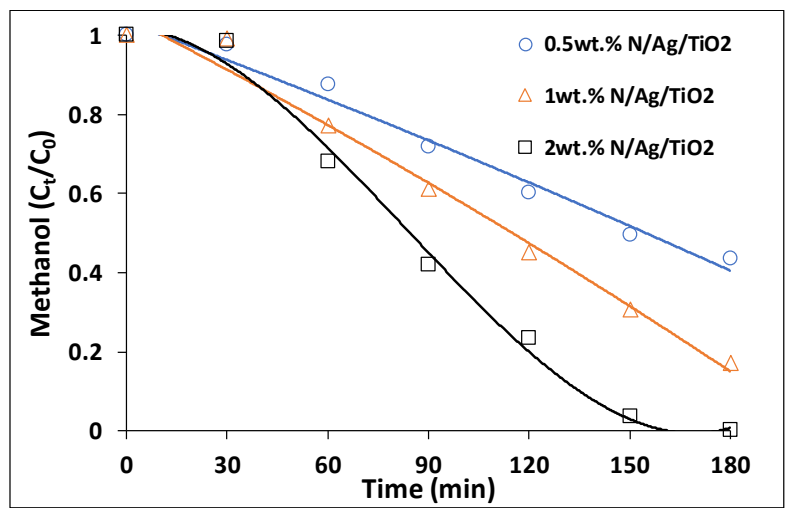

(a)

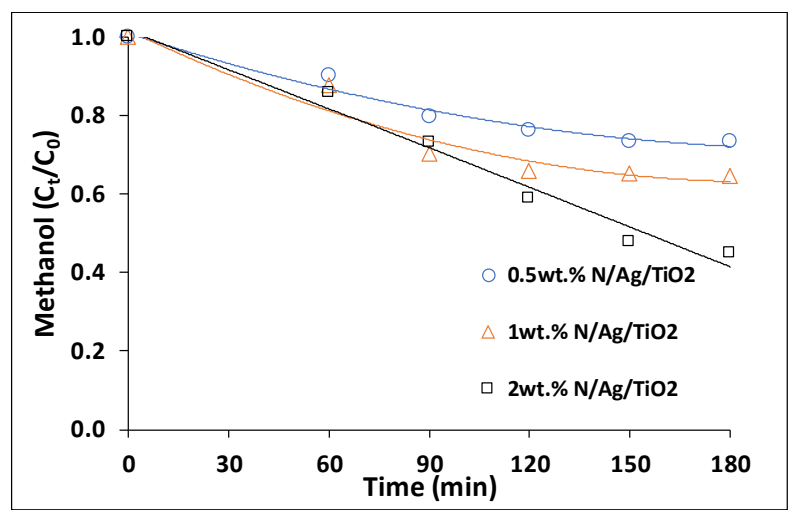

(b)

Figure 8. Methanol degradation with different loadings of $\mathrm{N} / \mathrm{Ag} / \mathrm{TiO}_{2}$ coated on a mesh: 0.5 wt. $\%, 1$ wt. $\%$ and 2 wt. $\%$ Runs were carried out under (a) near-UV light and (b) visible light irradiation. Note: Reported data are for at least three repeats with $15 \pm 5 \%$ standard deviation (SD). Note: The close to $100 \%$ recorded carbon contained balance shows the consistent accounting of all carbon containing species during the experiments.

Table 5. Methanol photodegradation rate under near-UV and visible light using a bare- $\mathrm{TiO}_{2}$ and $\mathrm{N} / \mathrm{Ag} / \mathrm{TiO}$ photocatalysts. The kinetic models used are of the pseudo first-order reaction type with kinetic constants being reported.

\begin{tabular}{|c|c|c|c|c|c|c|}
\hline \multirow{3}{*}{ Photocatalyst } & \multicolumn{2}{|c|}{ Degradation Rate (\%): Time (min) } & \multicolumn{4}{|c|}{ Kinetic Rate Constant } \\
\hline & \multirow{2}{*}{ Near UV Light } & \multirow{2}{*}{ Visible Light } & \multicolumn{2}{|c|}{ Near UV Light } & \multicolumn{2}{|c|}{ Visible Light } \\
\hline & & & $\min ^{-1}$ & $\mathbf{R}^{2}$ & $\min ^{-1}$ & $\mathbf{R}^{2}$ \\
\hline 0.5 wt. $\%$ bare $-\mathrm{TiO}_{2}$ & 100\%: $150 \mathrm{~min}$ & inactive & $9.4 \times 10^{-3}$ & 0.99 & - & - \\
\hline 1.0 wt. $\%$ bare $-\mathrm{TiO}_{2}$ & 100\%: $120 \mathrm{~min}$ & - & $1.3 \times 10^{-2}$ & 0.95 & - & - \\
\hline 2.0 wt. $\%$ bare $-\mathrm{TiO}_{2}$ & $100 \%: 90 \mathrm{~min}$ & - & $2.2 \times 10^{-2}$ & 0.98 & - & - \\
\hline 0.5 wt. $\%$ N/Ag $/ \mathrm{TiO}_{2}$ & $60 \%: 180 \mathrm{~min}$ & $30 \%: 180 \mathrm{~min}$ & $3.5 \times 10^{-3}$ & 0.98 & $1.6 \times 10^{-3}$ & 0.92 \\
\hline 1.0 wt. $\%$ N $/ \mathrm{Ag} / \mathrm{TiO}_{2}$ & $82 \%: 180 \mathrm{~min}$ & $40 \%: 180 \mathrm{~min}$ & $5.0 \times 10^{-3}$ & 0.98 & $2.1 \times 10^{-3}$ & 0.88 \\
\hline 2.0 wt. $\%$ N/Ag/ $/ \mathrm{TiO}_{2}$ & 100\%: $160 \mathrm{~min}$ & $60 \%: 180 \mathrm{~min}$ & $6.4 \times 10^{-3}$ & 0.96 & $3.3 \times 10^{-3}$ & 0.98 \\
\hline
\end{tabular}

Table 5 reports the photocatalytic performance of methanol degradation using the bare- $\mathrm{TiO}_{2}$ and the $\mathrm{N} / \mathrm{Ag} / \mathrm{TiO}_{2}$ and employing pseudo first-order reaction rates. Kinetic constants were also determined for each experimental condition, based on at least three repeats. Data obtained show higher kinetic constants at the higher photocatalyst loadings, with this being consistent with the increased photon absorption exposed area of the formed external agglomerate specific surface (refer to Figure 4). Therefore, based on these results, it was considered that $2 \mathrm{wt}$ \% was the best photocatalyst loading for next experiments in the present study. 


\subsubsection{Effect of Initial Methanol Concentration}

For methanol degradation, runs were performed by using different initial methanol concentrations of 25,45 and $90 \mu \mathrm{mol} / \mathrm{L}$ with $2 \mathrm{wt} . \%$ loadings of bare- $-\mathrm{TiO}_{2}$ and $\mathrm{N} / \mathrm{Ag} / \mathrm{TiO}_{2}$. Figure 9 shows that bare- $\mathrm{TiO}_{2}$ photocatalysts exhibited a maximum photocatalytic efficiency at $25 \mu \mathrm{mol} / \mathrm{L}$, with a slightly lower degradation rate with increasing methanol concentrations.

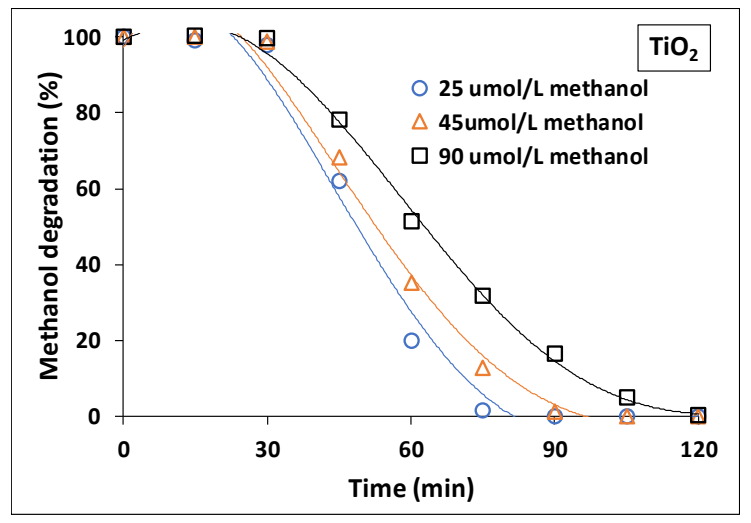

Figure 9. Photocatalytic performance of methanol degradation at different initial concentrations of methanol $(25,45$ and $90 \mu \mathrm{mol} / \mathrm{L})$ with 2 wt. $\%$ Bare- $-\mathrm{TiO}_{2}$ coated on a mesh under near-UV Light. Note: Reported data are for at least three repeats with $8 \pm 1 \%$ SD.

Figure 10a,b also display a maximum photocatalytic rate using $25 \mu \mathrm{mol} / \mathrm{L}$ of methanol, with $2 \mathrm{wt} . \% \mathrm{~N} / \mathrm{Ag} / \mathrm{TiO}_{2}$ coated on a mesh, with this being consistent for near-UV and visible light.

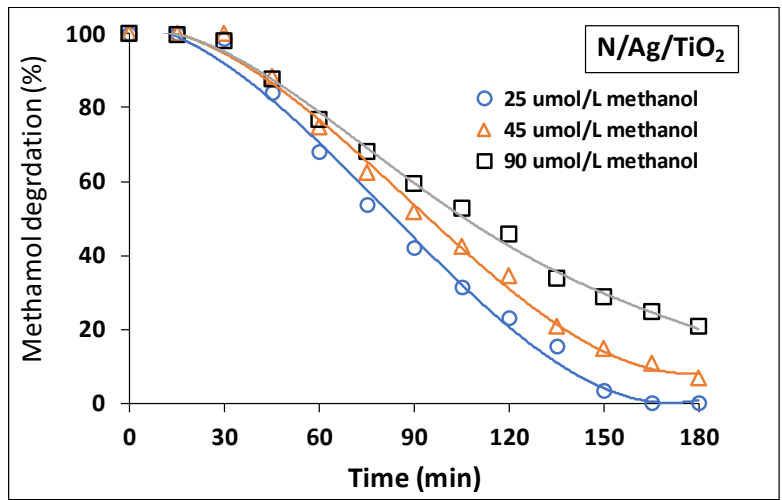

(a)

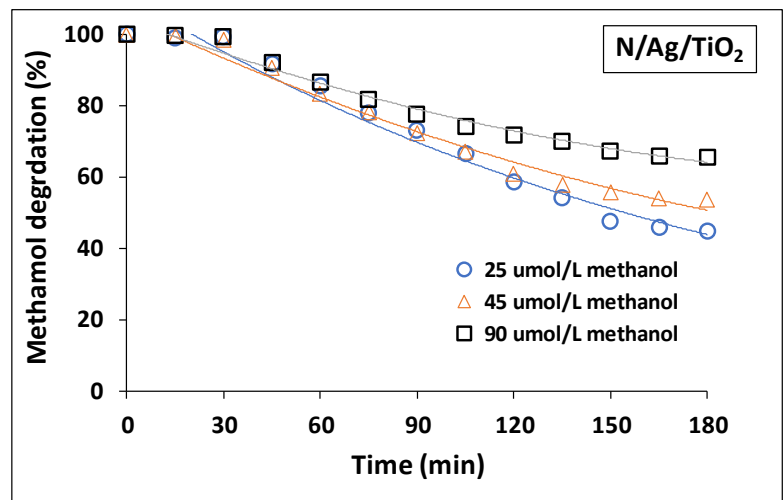

(b)

Figure 10. Photocatalytic performance of methanol degradation at three different initial concentrations of methanol (25, 45 and $90 \mu \mathrm{mol} / \mathrm{L}$ ) with $2 \mathrm{wt} . \% \mathrm{~N} / \mathrm{Ag} / \mathrm{TiO}_{2}$ coated on a mesh under (a) near-UV light and (b) visible light. Note: Reported data are for at least three repeats with $10 \pm 2 \%$ SD.

\subsubsection{Quantum Yield Efficiencies}

The quantum yield (QY) is a parameter that can be utilized to express the efficiency of the photocatalytic process (de Lasa et al. [19]). The QY can be calculated based on hydroxyl radical formation rates over the photocatalyst photon absorption rates. Figures 11 and 12 display the percentual quantum yields (QYs\%), for $2 \mathrm{wt.} \%$ of bare- $\mathrm{TiO}_{2}$ and $\mathrm{N} / \mathrm{Ag} / \mathrm{TiO}_{2}$ coated on the mesh, as a function of irradiation reaction time for the photodegradation of methanol at 25, 45 and $90 \mu \mathrm{mol} / \mathrm{L}$ concentrations. An example of a QY\% calculation is described in Appendix C. 


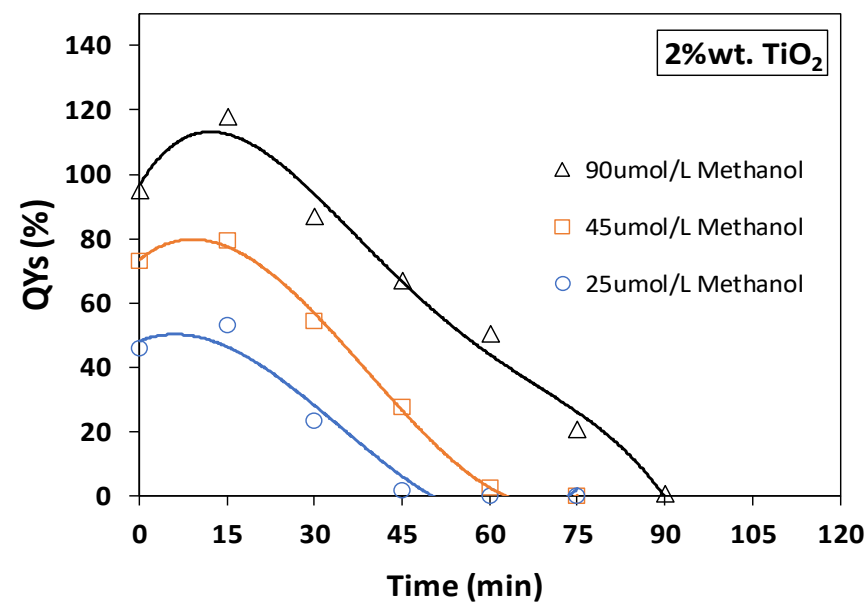

Figure 11. Quantum yield efficiencies (QYs\%) for photocatalytic methanol degradation using a $2 \mathrm{wt} . \%$ bare- $\mathrm{TiO}_{2}$ photocatalyst coated on a mesh. Experiments were carried out under near-UV light at three different initial methanol concentrations of 25, 45 and $90 \mu \mathrm{mol} / \mathrm{L}$. Note: Reported data are for at least three repeats with $8 \pm 1 \% \mathrm{SD}$.

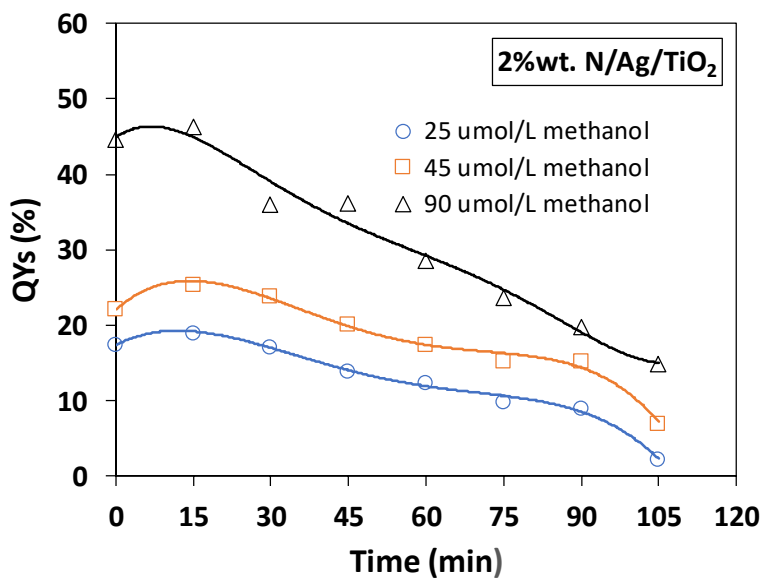

(a)

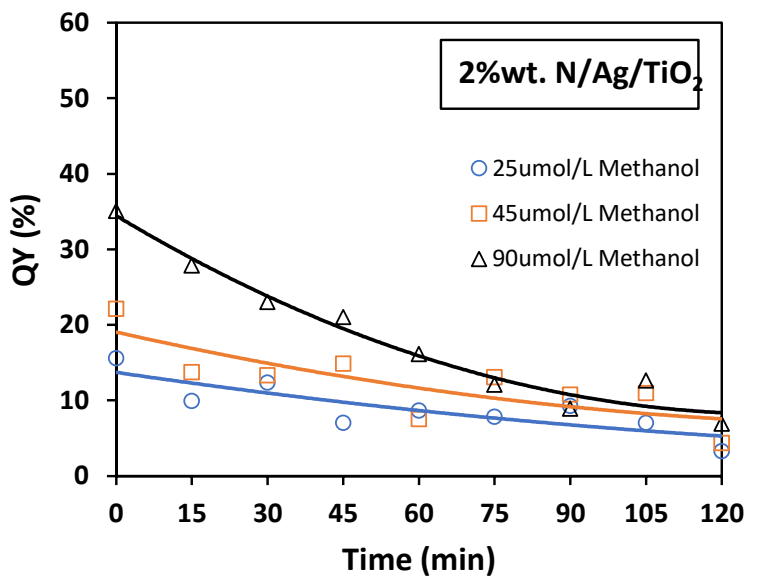

(b)

Figure 12. Quantum yields (QYs\%) for photocatalytic methanol degradation using a 2 wt.\% N/Ag/ $/ \mathrm{TiO}_{2}$ coated in a mesh. Runs were carried out using different irradiation sources: (a) near-UV light and (b) visible light, and at three different initial methanol concentrations of 25, 45 and $90 \mu \mathrm{mol} / \mathrm{L}$. Note: Reported data are for at least three repeats with $10 \pm 2 \%$ SD.

Figure 11 reports $\mathrm{QYs} \%$ for the bare- $\mathrm{TiO}_{2}$ under near-UV light irradiation, showing a QY\% increasing, with a maximum value after $15 \mathrm{~min}$ of irradiation. Then, the QYs\% steadily decrease until reaching zero, at the longer irradiation times. It is relevant to observe that at $90 \mu \mathrm{mol} / \mathrm{L}$, the QYs\% surpass $100 \%$, with this being consistent with results from Lugo Vega et al. [57] who used a Degussa P25 $\left(\mathrm{TiO}_{2}\right)$ photocatalyst in the Photo-CREC-Air, under near-UV light, for acetone photodegradation.

Figure $12 \mathrm{a}, \mathrm{b}$ report the $\mathrm{QYs} \%$ for the $\mathrm{N} / \mathrm{Ag} / \mathrm{TiO}_{2}$ under near-UV light and visible light irradiation, respectively. In Figure $12 \mathrm{a}$ for the N/Ag/ $\mathrm{TiO}{ }_{2}$ under near-UV light one can see that the photocatalytic degradation of methanol, achieved a maximum QY close to $50 \%$. This was twice as low as the QY\% obtained when using the bare- $\mathrm{TiO}_{2}$.

On the other hand, Figure $12 \mathrm{~b}$ shows the $\mathrm{QYs} \%$ when using a N/Ag/ $/ \mathrm{TiO}_{2}$ photocatalyst under visible light. In this case, the maximum QY\% was $35 \%$. This is in clear contrast with the essentially zero QY\% obtained when using the bare- $\mathrm{TiO}_{2}$ under visible irradiation.

Furthermore, Table 6 reports a comparison of QYs\% for photocatalytic methanol oxidation obtained using several photocatalyst loadings for both bare- $\mathrm{TiO}_{2}$ and $\mathrm{N} / \mathrm{Ag} / \mathrm{TiO}_{2}$ under visible and near-UV irradiation. 
Table 6. Percentage quantum yields (QYs\%) for the photocatalytic degradation of methanol $(90 \mu \mathrm{mol} / \mathrm{L})$ using either a bare- $\mathrm{TiO}_{2}$ photocatalyst or a $\mathrm{N} / \mathrm{Ag} / \mathrm{TiO}_{2}$ photocatalyst, coated on a mesh at different loadings: $0.5 \mathrm{wt} . \%, 1 \mathrm{wt} . \%$, and $2 \mathrm{wt} . \%$.

\begin{tabular}{ccc}
\hline \multirow{2}{*}{ Photocatalysts } & \multicolumn{2}{c}{ Maximum Quantum Yield Efficiencies (QYs\%) } \\
\cline { 2 - 3 } & Near-UV Light & Visible Light \\
\hline 0.5 wt.\% bare- $\mathrm{TiO}_{2}$ & 53.3 & - \\
1 wt.\% bare- $\mathrm{TiO}_{2}$ & 79.3 & - \\
2 wt. $\%$ bare$-\mathrm{TiO}_{2}$ & 117.9 & - \\
0.5 wt. $\% \mathrm{~N} / \mathrm{Ag} / \mathrm{TiO}_{2}$ & 19.0 & 15.69 \\
1 wt. $\% \mathrm{~N} / \mathrm{Ag} / \mathrm{TiO}_{2}$ & 25.3 & 20.54 \\
2 wt. $\% \mathrm{~N} / \mathrm{Ag} / \mathrm{TiO}_{2}$ & 46.3 & 35.08 \\
\hline
\end{tabular}

Table 6 shows for the 2 wt. $\%$ bare- $\mathrm{TiO}_{2}$, a highest QY\% of $117.9 \%$ under near-UV light was obtained. This QY\% is remarkably close to the theoretical maximum QY value of $133 \%$ [19]. Therefore, this result suggests that the photocatalytic methanol conversion with $2 \mathrm{wt} . \%$ bare- $\mathrm{TiO}_{2}$ and under near-UV light, is the recommended option to obtain the highest possible level of utilization efficiency in a Photo-CREC-AIR-Reactor. While this is encouraging, one should mention that the bare- $\mathrm{TiO}_{2}$ displays no activity under visible light.

On the other hand, for the $2 \mathrm{wt} . \% \mathrm{~N} / \mathrm{Ag} / \mathrm{TiO}_{2}$ photocatalyst, good photocatalytic performances were consistently observed in terms of methanol conversion, for both nearUV light as well as under visible light irradiation, these conversions being $46.3 \%$ QY and a $35.8 \%$ QY, respectively.

\section{Materials and Methods}

Both the bare- $\mathrm{TiO}_{2}$ and the $\mathrm{N} / \mathrm{Ag} / \mathrm{TiO}_{2}$ photocatalysts, were prepared via the solvothermal method. The prepared photocatalysts were immobilized on a cylinder of stainless-steel woven wire mesh using the spray coating method. This method is proposed here as an appropriate technique for coating a substrate material with a cylindrical shape. To optimize the immobilized photocatalyst loadings (0.5-2 wt.\%), different amounts of photocatalyst were coated on a woven stainless-steel mesh.

The conversion of methanol on the bare- $\mathrm{TiO}_{2}$ coated mesh, using either near-UV or visible light illumination, was carried out in the Photo-CREC-Air Reactor (Lugo-Vega et al. [57]). The light intensity and distribution over the coated mesh cylinder was measured using a Stellarnet Spectrophotoradiometer (EPP3000, 200-1100 nm wavelength range, StellarNet, Inc., Carlson Circle, Tampa, FL, USA). The efficiency of the photocatalysis of methanol conversion in the reactor was established using the QYs, based on the absorbed photons and the hydroxyl radicals consumed. The various steps of the experimental methods considered are described in more detail in the upcoming section.

\subsection{Preparation of Photocatalysts}

The bare- $\mathrm{TiO}_{2}$ as well as $\mathrm{N} / \mathrm{Ag} / \mathrm{TiO}_{2}$ photocatalysts, were synthesized by using solvothermal method. Using this approach, a titanium (IV) butoxide (Ti(OBu) $)_{4} \leq 97 \%$, Fluka, Buchs, Switzerland) precursor was dissolved in $110 \mathrm{~mL}$ of ethanol solvent $\left(\mathrm{C}_{2} \mathrm{H}_{5} \mathrm{OH}\right.$, $99.8 \%$, Merck, Darmstadt, Germany). This was followed by adding $1.26 \mathrm{~mL}$ of nitric acid $\left(\mathrm{HNO}_{3}, 65 \%\right.$, Merck) and distilled water $(3.6 \mathrm{~mL})$ under vigorous mixing. The resulting homogeneous gel was then transferred to a Teflon lined autoclave and kept in an oven (Wiseven WOF-105, Daihan Scientific, Seoul, Korea), under an air atmosphere and $200{ }^{\circ} \mathrm{C}$ for $3 \mathrm{~h}$. Furthermore, and to implement $\mathrm{Ag}$ and $\mathrm{N}$ doping, silver nitrate $\left(\mathrm{AgNO}_{3}, 99 \%\right.$, Merck, Darmstadt, Germany) and diethylamine $\left(\left(\mathrm{CH}_{3} \mathrm{CH}_{2}\right)_{2} \mathrm{NH}, 99 \%\right.$, Merck, Darmstadt, Germany) were employed as Ag and $\mathrm{N}$ sources. Under these conditions, silver nitrate and diethylamine solution was added dropwise into a bare- $\mathrm{TiO}_{2}$ solution prior to thermal treatment at $200{ }^{\circ} \mathrm{C}$ for $3 \mathrm{~h}$. Regarding $\mathrm{N}$ and $\mathrm{Ag}$ in $\mathrm{N} / \mathrm{Ag} / \mathrm{TiO}_{2}$, the precursor solutions were prepared to yield a nominal $5 \%$ and $10 \% \mathrm{~mol}$ in the synthesized semiconductor, re- 
spectively. Once the thermal treatment was complete, the precipitate obtained was filtered, repeatedly washed with ethanol-water and dried at $80^{\circ} \mathrm{C}$ overnight. The solid catalyst was finally ground in an agate mortar before annealing it at $450{ }^{\circ} \mathrm{C}$ for $3 \mathrm{~h}$, in a muffle furnace (JSMF-30HT, maximum temperature $1200^{\circ} \mathrm{C}$, JSR, Gongju, Korea) with a heating rate of $10^{\circ} \mathrm{C} / \mathrm{min}$. Further description of the reagents and methods used for photocatalysts synthesis are described in more detail in a recent publication (Sirivallop et al. [13]).

\subsection{Photocatalyst Characterization Methods}

The properties of the synthesized photocatalysts were characterized using XRD. With this end, an advance with Eulerian Cradle, Bruker, Madison, WI, USA unit with a $\mathrm{Cu}-\mathrm{K} \alpha$ radiation $\left(\lambda=1.5418 \AA\right.$ ) at $40 \mathrm{kV}$ source, recording a $2 \theta$ range in the $20^{\circ}-70^{\circ}$, was used. The XRD peak positions for the crystal phases were identified with the Joint Committee on Powder Diffraction Standards (JCPDS) database according to Sirivallop et al. [13]. The average crystallite size was determined using the Debye-Scherrer formula [29-31] below:

$$
D=\frac{K \lambda}{\beta_{h k l} \cos \theta}
$$

where $D$ is the average crystallite size (nm), $K$ is the shape factor $(0.89), \lambda$ is the wavelength of incident X-rays (1.5418 $\AA$ ), and $\beta_{h k l}$ is the full width at half maximum (FWHM) of the Bragg peak. One should mention that the average particle size distributions of the prepared bare- $\mathrm{TiO}_{2}$ and of the $\mathrm{N} / \mathrm{Ag} / \mathrm{TiO}_{2}$ were measured using a Malvern Zetasizer Nano-Series Analyzer (Malvern Panalytical Ltd., Worcestershire, UK).

On the other hand, the specific surface areas of the photocatalysts were determined from nitrogen adsorption-desorption isotherms at $77 \mathrm{~K}$, using a surface analyzer (Quantachrome, BEL model, Boynton Beach, FL, USA). The Brunauer-Emmett-Teller (BET) method was applied to calculate the surface areas, while the pore size diameters and volumes were determined by the Barrett-Joyner-Halenda (BJH) method. The total pore volume was estimated from the adsorbed amounts at the $0.98 \mathrm{P} / \mathrm{P}_{\mathrm{o}}$ relative pressure.

The optical properties of the bare- $\mathrm{TiO}_{2}$ and the $\mathrm{N} / \mathrm{Ag} / \mathrm{TiO}_{2}$ photocatalysts were investigated by using an ultraviolet/visible/near-infrared (UV/Vis/NIR) spectrophotometer (Perkin Elmer, Lambda 950, Waltham, MA, USA) at the wavelength range of 200-700 nm. The band gap energy $\left(\mathrm{E}_{\mathrm{g}}\right)$ of both photocatalysts was estimated using the Tauc-method, by plotting the $(\alpha h v)^{2}$ versus the photon energy (hv) [58]. In addition, the electronic structure and electron-hole separation were analyzed using the photoluminescence (PL) spectrophotometer (AvaSpec-2048TEC-USB2-2, Avantes, Apeldoorn, The Netherlands) under the excitation of a 20 microwatt light-emitting diode (LED) lamp. The chemical composition and state of the $\mathrm{Ag}$ and $\mathrm{N}$ in the bare- $\mathrm{TiO}_{2}$ crystal lattice were analyzed by X-ray photoelectron spectroscopy (XPS) using a Thermoscientific ESCALAB 250Xi system with a $\mathrm{Mg} \mathrm{K} \alpha$ source (Thermo Fisher Scientific, Waltham, MA, USA). All the binding energies were calibrated using the $\mathrm{C} 1$ s peak at $284.6 \mathrm{eV}$.

Furthermore, and to establish the relative abundance of the acid sites on the photocatalyst surface, ammonia $\left(\mathrm{NH}_{3}\right)$ TPD was performed by using a Micromeritics Autochem II 2920 instrument (Norcross, GA, USA). In the TPD procedure, the prepared photocatalysts were pretreated with a flow of helium $(\mathrm{He})$ at $600{ }^{\circ} \mathrm{C}$ for $20 \mathrm{~min}$ and then cooled down to $100{ }^{\circ} \mathrm{C}$. After this, a stream of gas containing $5 \% \mathrm{NH}_{3}$ balanced with $\mathrm{He}$, was circulated through two beds containing $178 \mathrm{mg}$ and $183 \mathrm{mg}$ of synthesized bare- $\mathrm{TiO}_{2}$ and $\mathrm{N} / \mathrm{Ag} / \mathrm{TiO}_{2}$, respectively, at a rate of $\sim 50 \mathrm{~cm}^{3} / \mathrm{min}$ and heated at $100{ }^{\circ} \mathrm{C}$ for $1 \mathrm{~h}$. Then, the photocatalyst samples were heated using a $20{ }^{\circ} \mathrm{C} / \mathrm{min}$ ramp, from ambient to $600{ }^{\circ} \mathrm{C}$, under helium flow. $\mathrm{NH}_{3}$ was then progressively released from the sample, once the sample temperature provided the required ammonia desorption energy. TPD was then employed to quantify the desorbed $\mathrm{NH}_{3}$ from the photocatalyst samples. As a result, the total acidity of the sample was determined by integrating the eluted ammonia peak, which represented the volumetric change of $\mathrm{NH}_{3}$ in $\mathrm{cm}^{3} / \min (\mathrm{STP})$. 


\subsection{Spray Coating for Photocatalyst Immobilization}

Good mesh coatings should provide a uniform and homogenous photocatalyst layer. The resulting coating should provide a large of surface area with little particle agglomeration. In this respect, spray coating techniques show great potential with neither binder nor polymer required due to the interparticular-forces between bare- $\mathrm{TiO}_{2}$ photocatalysts and stainless-steel woven mesh [59].

A 304 stainless-steel cylindrical woven wire mesh (Ferrier Wire Goods Co., Toronto, ON, Canada) with a $1220 \mathrm{~cm}^{2}$ total area, a $0.01 \mathrm{~mm}$ wire diameter, a $40 \times 40$ mesh count and $36 \%$ open area, was used as the substrate material in this research. The immobilization of the photocatalyst on the stainless-steel woven mesh cylinder was obtained by using the spray coating technique which was adapted from Lugo-Vega et al. [59]. These authors reported that spray coating provides an appropriate technique for $\mathrm{TiO}_{2}$ photocatalyst immobilization on complex substrates such as metallic meshes, without blocking the mesh openings and without affecting the pressure drop significantly.

The apparatus described in Figure 13 was used by adopting the following photocatalyst immobilization steps:

i. A cylindrical shaped mesh was cleaned with acetone, alcohol and deionized water to remove all dirt, oils or grease, before letting it dry.

ii. A cleaned cylindrical shaped stainless-steel woven mesh was set on a rotating base with a constant velocity of 12 rpm. A 150 Badger nozzle gun (Badger Air-Brush Co., Franklin Park, IL, USA) was held on a stand, which was fixed at a distance of $30 \mathrm{~cm}$ from the cylinder mesh surface.

iii. The bare- $\mathrm{TiO}_{2}$ or $\mathrm{N} / \mathrm{Ag} / \mathrm{TiO}_{2}$ particle suspension with different concentrations $(5,10$ and $20 \mathrm{wt} . \%)$ were prepared using distilled water $(50 \mathrm{~mL})$, by sonicating the particle slurries for $30 \mathrm{~min}$. Furthermore, and to avoid the particle settling during spray coating, the particle suspension was stirred continuously using a magnetic stirrer.

iv. A $1.31 \mathrm{~mL}$ suspension volume was injected into a paint cup and then sprayed onto the mesh surface with an adequate and constant air pressure of $20 \mathrm{psia}$. This required coating was typically achieved after three-cylinder rotations, with the spray gun providing a homogeneous coating to all areas of the metallic mesh (Figure 14). To cover the entire height of the cylindrical mesh, the gun level was adjusted for every coating step, starting from the top and moving down every $5 \mathrm{~cm}$.

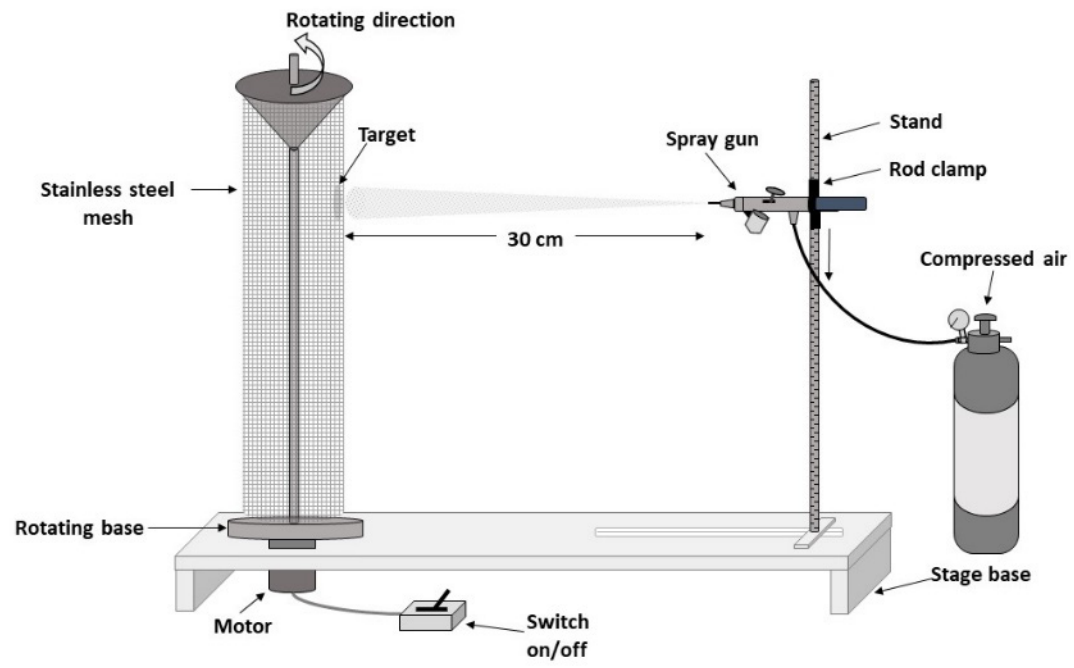

Figure 13. Schematic diagram of the immobilization of the photocatalyst on a stainless steel woven wire mesh cylinder via an air assisted spray coating technique adapted from Lugo-Vega et al. [59]. 


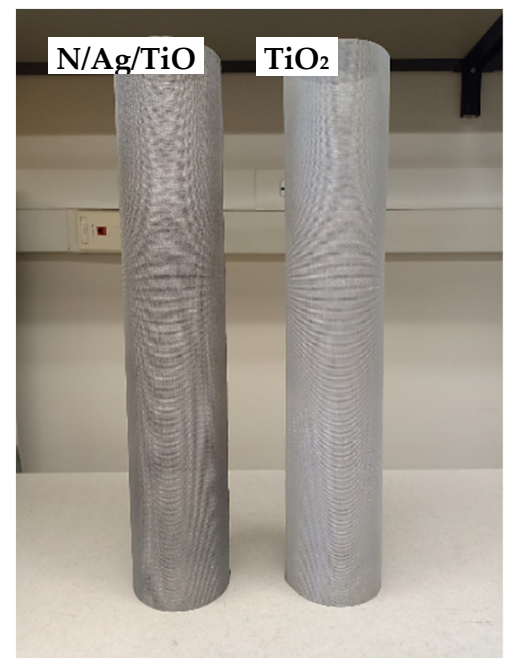

Figure 14. Photos showing the cylindrical stainless-steel woven mesh $(55.4 \mathrm{~cm} \times 34.7 \mathrm{~cm})$ with the immobilized $\mathrm{N} / \mathrm{Ag} / \mathrm{TiO}_{2}$ and bare- $\mathrm{TiO}_{2}$ photocatalysts.

The mass of the photocatalyst coated on the cylindrical mesh was determined by the weight difference before and after coating. It was found that $1 \mathrm{~g}$ of immobilized photocatalyst could be coated on a $220 \pm 0.2 \mathrm{~g}$ of stainless-steel woven mesh, using $2.5 \mathrm{~g}$ of photocatalyst dispersed in $50 \mathrm{~mL}$ of water.

Using the proposed impregnation method, the photocatalyst coated with immobilized photocatalyst on the wire mesh as shown in Figure 14 was obtained. This was achieved with a spray coating efficiency of about $40 \mathrm{wt} . \%$.

Furthermore, and to investigate the optimal amount of photocatalyst immobilized on the mesh, three different amounts of bare- $\mathrm{TiO}_{2}$ and $\mathrm{N} / \mathrm{Ag} / \mathrm{TiO}_{2}$ suspensions were prepared: $0.5 \mathrm{wt} . \%, 1 \mathrm{wt} \% \%$ and $2 \mathrm{wt} . \%$ Moreover, the strength of the photocatalyst particle attachment on the stainless-steel woven mesh was evaluated by exposing the coated mesh to the airflow system in the Photo-CREC-Air Reactor for $48 \mathrm{~h}$. One should note that the weight of the immobilized mesh before and after testing was essentially unchanged, with a $0.02 \pm 0.01 \%$ weight loss only.

\subsection{Photocatalytic Conversion of Methanol in the Photo-CREC-Air Reactor (PCAR)}

The Photo-CREC-Air Reactor (55 L total volume) operates at isothermal conditions $39 \pm 0.5^{\circ} \mathrm{C}$. It was designed for the photocatalytic degradation of several VOCs pollutants, using an irradiated cylinder mesh with an immobilized photocatalyst. The PCAR was employed for the conversion of methanol, in this present work.

Figure 15 describes a simplified scheme of the overall view of a Photo-CREC-Air Reactor. The Photo-CREC-Air Reactor consists of three major sections: (1) an air transfer section, using a GASP gas blower to drive the air to the Venturi and to the reaction section, (2) a water-cooling section which controls the temperature before recirculating the air into the reaction section, and (3) a reaction section with a coated mesh inside a quartz glass tube, surrounded by eight light lamps, ensuring adequate irradiation to the coated mesh. The cylindrical stainless-steel woven mesh is supported by a bullet nose bottom, which promotes the appropriate airflow recirculation through the coated mesh (Figure 15, inset).

The experiments of methanol conversion in a Photo-CREC-Air Reactor were carried out by using either a bare- $\mathrm{TiO}_{2}$-coated mesh or $\mathrm{N} / \mathrm{Ag} / \mathrm{TiO}$-coated mesh, under the irradiation of 8 near-UV lamps (Philips, Amsterdam, the Netherlands, $15 \mathrm{~W}, 325-380 \mathrm{~nm}$ wavelength) or 8 visible light lamps (Eiko Global, Shawnee, KS, USA, 15 W, 360-800 nm wavelength). Before the light was turned on, the experiment was run under dark conditions for $30 \mathrm{~min}$. This was done in order to reach the adsorption equilibrium between the organic pollutants and the photocatalyst. Regarding the runs developed, experiments involved varying the quantity of photocatalyst loading $(0.5,1$ and $2 \mathrm{wt}$. $\%)$ and the methanol 
concentration $(25,45$, and $90 \mu \mathrm{mol} / \mathrm{L})$. Every experimental condition was repeated at least three times, to secure adequate data collection. Before every experimental run, air in the photoreactor reactor loop was allowed to flow, with the "on-off" valve opened for an hour. This permitted the evacuation of any chemical species that could have remained in the Photo-CREC-Air Reactor from a previous run.

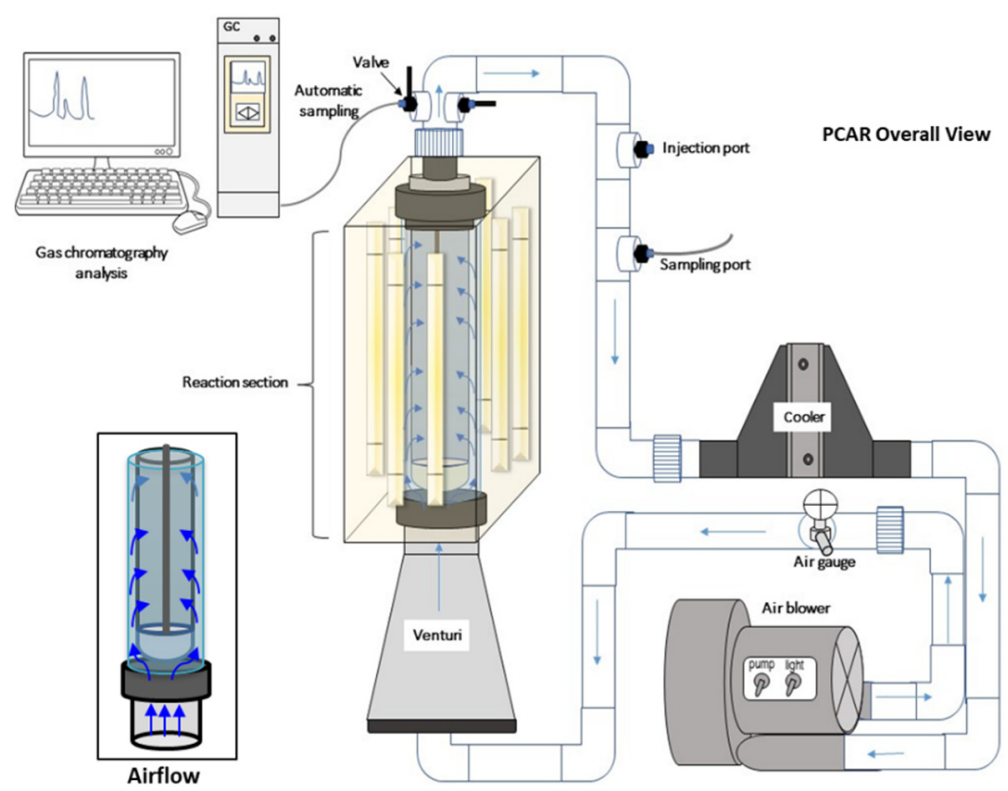

Figure 15. Schematics of a Photo-CREC-Air Reactor system with gas chromatography equipment. This figure also describes the air circulation (Airflow) through the stainless-steel woven coated mesh (inset).

The concentrations of methanol and of photocatalytic intermediates at various irradiation times, were quantified using an automatic sampling valve connected to a gas chromatographic (GC) unit. This GC was equipped with a flame ionization detector (FID). The GC-FID methods employed are described in Supplementary Materials A and B.

\subsection{Radiation Measurements and Macroscopic Irradiation Energy Balances}

Irradiation measurements in the Photo-CREC-AIR Reactor unit are of prime importance to establish macroscopic energy balances [19]; incident photons $\left(P_{i}\right)$ are absorbed, backscattered, and transmitted by the photocatalyst impregnated mesh, as described in Figure 16.

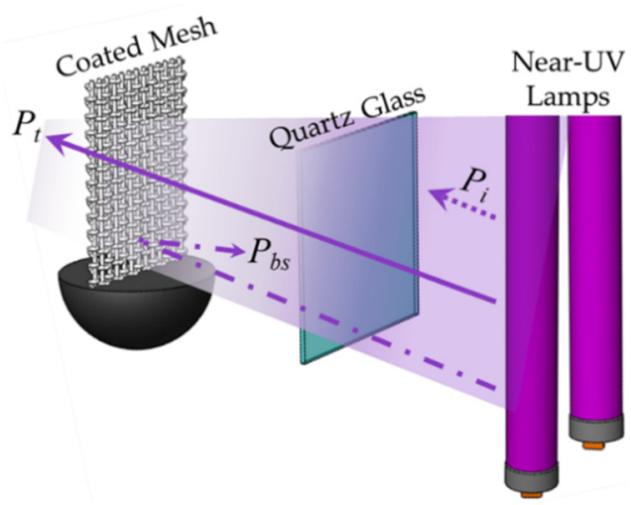

Figure 16. Schematic diagram of light photons irradiation, showing incident light $\left(\mathrm{P}_{\mathrm{i}}\right)$, transmitted light $\left(\mathrm{P}_{\mathrm{t}}\right)$ and backscattered light $\left(\mathrm{P}_{\mathrm{bs}}\right)$, resulting from the interaction with the immobilized photocatalyst on Photo-CREC-Air Reactor mesh. 
To establish photon absorption in the photocatalyst, measurements of incident light, transmitted light through the mesh, and backscattered light were carried out at several axial and angular positions. This allowed us to establish macroscopic radiation balances as follows:

$$
\begin{aligned}
P_{i} & =P_{a}+P_{t}+P_{b s} \\
P_{a} & =P_{i}-P_{t}-P_{b s}
\end{aligned}
$$

where, $P_{i}$ is the rate of incident light, $P_{a}$ is the rate of absorbed photons by the photocatalyst, $\mathrm{P}_{t}$ is the rate of transmitted photons by the photocatalysts and $\mathrm{P}_{\mathrm{bs}}$ is the rate of backscattered photons by the photocatalyst. One should note that the photon flux for $P_{i}, P_{t}$ and $P_{b s}$ in photons $\mathrm{s}^{-1}$ can be calculated using following equation:

$$
\mathrm{P}=\frac{Q}{E_{a v}}
$$

The total photon energy $(\mathrm{Q})$ in the reactor can be calculated by integrating the spectral irradiance overall photon wavelengths and multiplying this by the irradiated area of a cylindrical mesh as shown in Equation (18). On this basis, the average photon energy $\left(E_{a v}\right)$ in J/photon can be obtained by using Equation (19) [60,61].

$$
\begin{gathered}
\mathrm{Q}=\int_{\lambda_{\min }}^{\lambda_{\max }} \int_{0}^{\infty} \int_{0}^{2 \pi} q(\theta, z, \lambda) r d \theta d z d \lambda \\
E_{a v}=\frac{\frac{\lambda}{h c} \int_{\lambda_{\min }}^{\lambda_{\max }} q(\theta, z, \lambda) d \lambda}{\int_{\lambda_{\min }}^{\lambda_{\max }} q(\theta, z, \lambda) d \lambda}
\end{gathered}
$$

According to Equation (17), it can be rewritten with the use of Equations (18) and (19) as follows,

$$
\mathrm{P}=\frac{\int_{\lambda_{\min }}^{\lambda_{\max }} \int_{0}^{\infty} \int_{0}^{2 \pi} q(\theta, z, \lambda) r d \theta d z d \lambda}{E_{a v}}
$$

or,

$$
\mathrm{P}=\frac{\lambda}{h c} \int_{\lambda_{\min }}^{\lambda_{\max }} \int_{0}^{\infty} \int_{0}^{2 \pi} q(\theta, z, \lambda) r d \theta d z d \lambda
$$

where $\mathrm{Q}$ or $q(\theta, z, \lambda)$ represents the energy from the lamp in $\mathrm{J} \mathrm{s}^{-1}$ units, measured at different angular $(\theta)$, radial $(r)$ and axial $(z)$ positions; where $P$ is the photon flux (photon $\mathrm{s}^{-1}$ ); where $E_{a v}$ stands for the average photon energy (J/photon); where $\lambda$ is the photon wavelength $(\mathrm{nm})$; where $h$ is the Planck's constant $\left(6.34 \times 10^{-34} \mathrm{~J} \mathrm{~s} /\right.$ photon $)$; and where $c$ the speed of light $\left(3.0 \times 10^{8} \mathrm{~m} \mathrm{~s}^{-1}\right)$.

To calculate the various irradiation terms as shown in Figure 16, and to obtain a value for $\mathrm{P}_{\mathrm{a}}$, a Stellarnet Spectrometer (EPP3000, 200-1100 nm wavelength range, Carlson Circle Tampa, FL, USA) connected with an optical probe, was employed. The sensing end of this spectroradiometer was adapted, so that it could be inserted into the reaction section of the reactor from the top of the quartz glass tube. As a result, we were able to develop radiation measurements, at several axial and angular positions in the Photo-CREC-Air unit, as required by Equation (15). The spectral intensity of near-UV (320-400 $\mathrm{nm}$ wavelength) and visible light (380-800 $\mathrm{nm}$ wavelength) lamps measured by a Stellarnet Spectrometer is shown in Appendix A. Additional information regarding radiation measurements and other auxiliary equipment are reported in more detail by Lugo-Vega [57].

\subsection{Quantum Yield Efficiencies}

The quantum yield (QY) is a key parameter used to establish the performance of a photocatalytic reactor (de Lasa et al. [19]). The QY can be defined as the ratio of the moles of $\mathrm{OH}^{\bullet}$ radicals involved in the photocatalytic reaction over the number of moles 
of photons absorbed by photocatalyst [61]. Thus, the QY can be calculated as reported in Equation (22) [60,61]:

$$
\text { Quantum yield }(\mathrm{QY})=\frac{\text { rate of } \mathrm{OH}^{\bullet} \text { consumed }}{\text { rate of photon absorbed }}
$$

The rate of $\mathrm{OH}^{\bullet}$ consumption can be calculated using the stoichiometry of pollutant degradation as follows:

$$
\begin{aligned}
v_{i, j} \mathrm{C}_{\mathrm{n}} \mathrm{H}_{\mathrm{m}} \mathrm{O}_{\mathrm{o}}+v_{\mathrm{OH}^{\bullet}, \mathrm{j}} \mathrm{OH}^{\bullet} & \rightarrow v_{\mathrm{h}, \mathrm{j}} \mathrm{C}_{\mathrm{x}} \mathrm{H}_{\mathrm{y}} \mathrm{O}_{\mathrm{z}}+v_{\mathrm{H}_{2} \mathrm{O}, \mathrm{j}} \mathrm{H}_{2} \mathrm{O} \\
\frac{\mathrm{r}_{i, j}}{\mathrm{v}_{\mathrm{i}, \mathrm{j}}} & =\frac{\mathrm{r}_{\mathrm{OH}^{\bullet}, \mathrm{j}}}{\mathrm{v}_{\mathrm{OH}^{\bullet}, \mathrm{j}}} \\
\mathrm{r}_{\mathrm{OH}}, \mathrm{j} & =\frac{\mathrm{v}_{\mathrm{OH}^{\bullet}, \mathrm{j}}}{\mathrm{v}_{\mathrm{i}, \mathrm{j}}} \mathrm{r}_{\mathrm{i}, \mathrm{j}}
\end{aligned}
$$

where, $\mathrm{r}_{i, j}$ and $\mathrm{r}_{\mathrm{OH}}{ }^{\bullet}, \mathrm{j}$ stand for the $\mathrm{C}_{\mathrm{n}} \mathrm{H}_{\mathrm{m}} \mathrm{O}_{\mathrm{o}}$ and $\mathrm{OH}^{\bullet}$ consumption rates, respectively; and where $v_{i, j}$ and $v_{\mathrm{OH}^{\bullet}, j}$ represent the stoichiometric coefficients for $\mathrm{C}_{\mathrm{n}} \mathrm{H}_{\mathrm{m}} \mathrm{O}_{\mathrm{o}}$ and $\mathrm{OH}^{\bullet}$ at step $\mathrm{j}$, respectively.

Thus, and to be able to calculate the total rate of $\mathrm{OH}^{\bullet}$ consumed, one should consider the summation of all $\mathrm{OH}^{\bullet}$ depleted, at every photocatalytic step as follows:

$$
\mathrm{r}_{\mathrm{OH}^{\bullet}, \mathrm{T}}=\sum \mathrm{r}_{\mathrm{OH}}, \mathrm{j}=\sum \frac{\mathrm{v}_{\mathrm{OH}}, \mathrm{j}}{\mathrm{v}_{\mathrm{i}, \mathrm{j}}} \mathrm{r}_{\mathrm{i}, \mathrm{j}}
$$

Hence, the QY calculation for overall reaction should be as shown in Equation (27).

$$
\mathrm{QY}=\frac{\sum_{1}^{\mathrm{j}} \mathrm{r}_{\mathrm{OH}^{\bullet}, \mathrm{j}}}{\mathrm{P}_{\mathrm{abs}}}=\frac{\sum_{1}^{\mathrm{j}} \frac{\mathrm{v}_{\mathrm{OH}}{ }^{\bullet}, \mathrm{j}}{\mathrm{v}_{\mathrm{i}, \mathrm{j}}}}{\mathrm{P}_{\mathrm{abs}}} \mathrm{r}_{\mathrm{i}, \mathrm{j}}
$$

\section{Conclusions}

(a) It was shown that an air-assisted spray coating technique is effective to coat a $\mathrm{N} / \mathrm{Ag} / \mathrm{TiO}_{2}$ photocatalyst on a cylindrical stainless-steel woven wire mesh.

(b) It was demonstrated that a coated $\mathrm{N} / \mathrm{Ag} / \mathrm{TiO}_{2}$ photocatalyst in a stainless-steel woven wire mesh in a Photo-CREC-Air unit is effective in decomposing methanol under both near-UV and visible light.

(c) It was proven that a stainless-steel woven mesh immobilized $\mathrm{N} / \mathrm{Ag} / \mathrm{TiO}_{2}$ at $2 \mathrm{wt} . \%$ loading in the Photo-CREC-Air Reactor, provides a best photocatalytic activity with $60 \%$ methanol conversion and a best QY\% of $35.08 \%$, under the visible light during 180 min of irradiation time.

(d) It was proven that in contrast, a stainless-steel woven wire mesh immobilized bare$\mathrm{TiO}_{2}$ in a Photo-CREC-Air unit exhibits excellent photocatalytic activity under nearUV light showing 100\% methanol (25-90 $\mu \mathrm{mol} / \mathrm{L})$ decomposition within $3 \mathrm{~h}$ and a greatest QY\% of $117.9 \%$. This photocatalyst is, however, essentially inactive under visible light.

(e) It was shown that the band gap energy, the specific surface area, the external agglomerate specific surface and surface acidity, are all critical importance for determining $\mathrm{N} / \mathrm{Ag} / \mathrm{TiO}_{2}$ photocatalyst performance under visible light.

Supplementary Materials: The following are available online at https: / www.mdpi.com/article/ 10.3390/catal11050529/s1, Figure S1: GC parameters of the column separation method; Figure S2: Calibration Curves for (a) methanol (0-450 $\mu \mathrm{mol} / \mathrm{L})$ and (b) $\mathrm{CO}_{2}(0-150 \mu \mathrm{mol} / \mathrm{L})$; Figure S3: Typical Chromatograms for Methanol $\left(\mathrm{CH}_{3} \mathrm{OH}\right)$ and $\mathrm{CO}_{2}$ Obtained from a GC-FID; Figure S4: SEM images of (a) bare- $\mathrm{TiO}_{2}$ and (b) $\mathrm{N} / \mathrm{Ag} / \mathrm{TiO}_{2}$ photocatalysts. (c) EDX spectrum of $\mathrm{N} / \mathrm{Ag} / \mathrm{TiO}_{2}$ photocatalyst. The inset table shows the compositional ratio of elemental $\mathrm{O}, \mathrm{Ti}, \mathrm{Ag}, \mathrm{N}$ in $\mathrm{N} / \mathrm{Ag} / \mathrm{TiO}_{2}$. (d) EDX 
mapping of elemental $\mathrm{O}, \mathrm{Ti}, \mathrm{Ag}$ and $\mathrm{N}$ in $\mathrm{N} / \mathrm{Ag} / \mathrm{TiO}_{2}$ photocatalyst; Figure S5: Photoluminescence (PL) spectra of bare- $\mathrm{TiO}_{2}$ and $\mathrm{N} / \mathrm{Ag} / \mathrm{TiO}_{2}$ photocatalysts.

Author Contributions: Investigation methodology, data curation, data analysis, writing-original draft A.S.; conceptualization, methodology, data analysis, visualization, writing-review and editing, co-supervision S.E.; investigation, methodology, data curation and analysis, T.A.; investigation, data analysis, funding, methodology, writing-review, co-supervision S.C.; conceptualization, investigation, formal analysis, funding, first draft writing-review and editing, co-supervision: H.d.L.; All authors have read and agreed to the published version of the manuscript.

Funding: This research was funded by the King Mongkut's University of Technology Thonburi via the Petchra Pra Jom Klao Doctoral Degree Research Scholarship and Natural Science and Engineering Research Council of Canada, H.d.L. NSERC Discovery grant number.

Acknowledgments: Adilah Sirivallop would like to express her gratitude The Joint Graduate School of Energy and Environment, King Mongkut's University of Technology Thonburi and to the University of Western Ontario, Canada for her financial supports. She would also like to thank the Center of Excellence on Energy Technology and Environment (CEE), PERDO, Ministry of Higher Education, Science, Research and Innovation for the financial support provided to perform this study. As well, the authors would like to acknowledge Florencia de Lasa for her assistance in the editing and proofreading of this manuscript.

Conflicts of Interest: The authors declare no conflict of interest.

\section{Nomenclature}

\begin{tabular}{|c|c|c|}
\hline \multicolumn{3}{|l|}{ Symbols } \\
\hline $\mathrm{Ag}$ & silver & \\
\hline $\mathrm{C}$ & concentration & $\mathrm{mol} \mathrm{L}^{-1}$ \\
\hline $\mathrm{C}_{0}$ & initial concentration & $\mathrm{mol} \mathrm{L}^{-1}$ \\
\hline $\mathrm{C}_{\mathrm{t}}$ & concentration at $\mathrm{t}$ time & $\mathrm{mol} \mathrm{L}^{-1}$ \\
\hline $\mathrm{CH}_{3} \mathrm{OH}$ & methanol & \\
\hline $\mathrm{CO}_{2}$ & carbon dioxide & \\
\hline $\mathrm{e}^{-}$ & electron & \\
\hline$E_{a v}$ & average energy of photon & J photon $^{-1}$ \\
\hline $\mathrm{Eg}$ & energy band gap & $\mathrm{eV}$ \\
\hline $\mathrm{h}^{+}$ & positive hole & \\
\hline $\mathrm{h}$ & height & $\mathrm{cm}$ \\
\hline $\mathrm{H}_{2} \mathrm{O}$ & water & \\
\hline $\mathrm{HCHO}$ & formaldehyde & \\
\hline $\mathrm{HCOOH}$ & formic acid & \\
\hline $\mathrm{N}$ & nitrogen & \\
\hline $\mathrm{OH}$. & hydroxyl radical & \\
\hline $\mathrm{O}_{2}$ & oxygen & \\
\hline $\mathrm{P}$ & rate of photon & photon $\mathrm{s}^{-1}$ \\
\hline$P_{i}$ & rate of incident photons & photon $\mathrm{s}^{-1}$ \\
\hline $\mathrm{P}_{\mathrm{t}}$ & rate of transmitted photons & photon $\mathrm{s}^{-1}$ \\
\hline $\mathrm{P}_{\mathrm{bs}}$ & rate of back scattered photons & photon $\mathrm{s}^{-1}$ \\
\hline $\mathrm{P}_{\mathrm{abs}}$ & rate of absorbed photons & photon $\mathrm{s}^{-1}$ \\
\hline $\mathrm{Q}$ & photon energy & $\mu \mathrm{W}^{2} \mathrm{~cm}^{-2}$ \\
\hline $\mathrm{r}$ & reaction rate & \\
\hline $\mathrm{t}$ & time & $\min$ \\
\hline $\mathrm{TiO}_{2}$ & titanium dioxide & \\
\hline $\mathrm{z}$ & axial coordinate & $\mathrm{cm}$ \\
\hline Greek sym & & \\
\hline$\theta$ & angle & \\
\hline$v$ & frequency of incident photon & $v(\lambda)=c / \lambda$ \\
\hline$c$ & speed of ligh & $2.99 \times 10^{8} \mathrm{~m} \mathrm{~s}^{-1}$ \\
\hline$\lambda$ & wavelength & $\mathrm{nm}$ \\
\hline$h$ & planck's constant & $6.63 \times 10^{-34} \mathrm{~J} \mathrm{~s}^{-1}$ \\
\hline
\end{tabular}




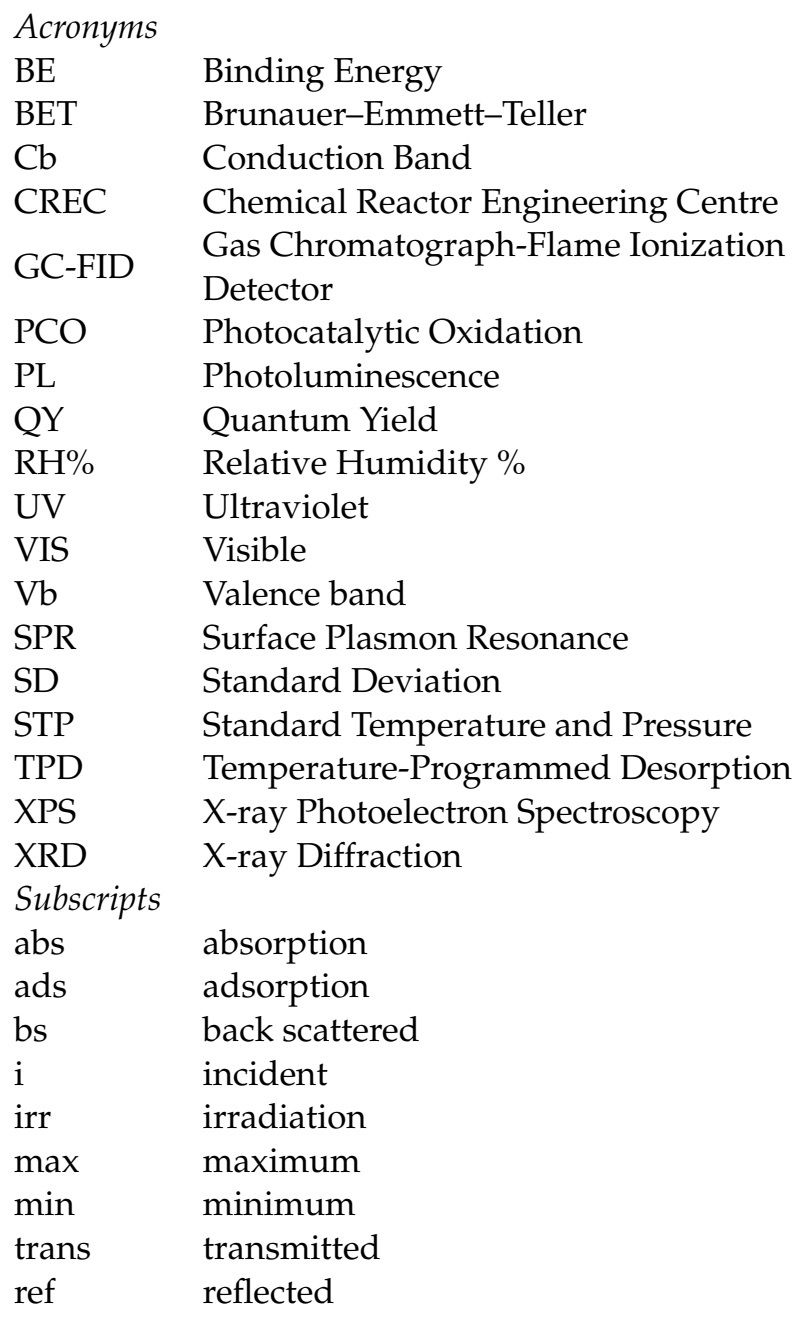

Appendix A. Near-Ultraviolet (UV) and Visible Light Spectra

Figure A1 represents the spectrum for the near-UV light and the visible light from 300 to $800 \mathrm{~nm}$ range.

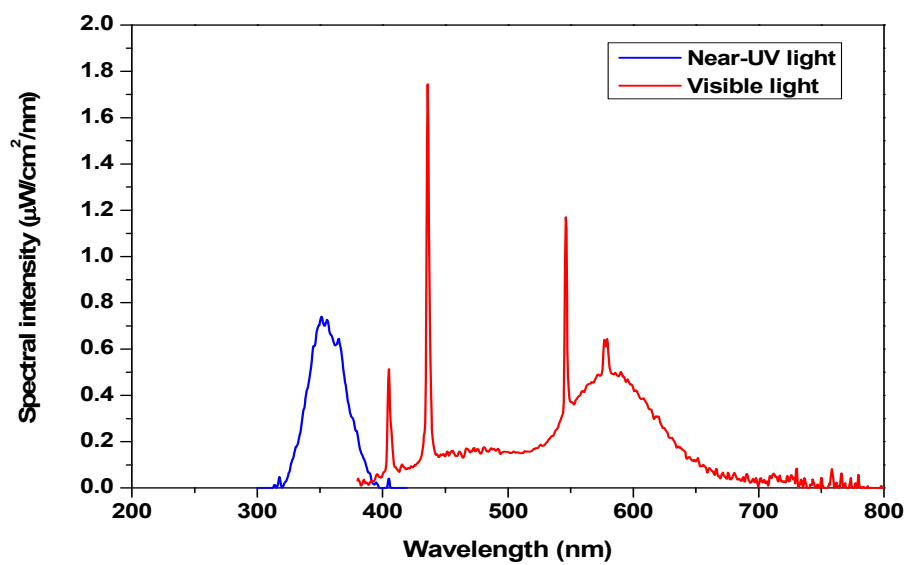

Figure A1. Spectral intensity of near-UV and visible light lamps measured by a Stellarnet Spectrometer (EPP3000, 200-1100 nm wavelength range).

Appendix B. Relative Humidity Analysis in the Photo-CREC Air Reactor (PCAR)

A calibration was performed in the PCAR to quantify the relative humidity $(\mathrm{RH})$ of air streams. The RH is an important parameter to be considered to determine whether the 
water vapor in the PCAR has an effect on the photocatalytic activity. The RH data were taken with a hygrometer (Mengshen digital humidity meter) at different known water concentrations. The hygrometer operates from 0 to $100 \% \mathrm{RH}$ and -20 to $80{ }^{\circ} \mathrm{C}$ range, respectively. Furthermore, its humidity accuracy is $\pm 3 \% \mathrm{RH}$ and the resolution falls into $0.01 \% \mathrm{RH}$ or $0.01^{\circ} \mathrm{C}$.

Figure A2 shows a pinkish-shaded band which represents the operational relative humidity range, $35 \%$ to $46 \%$. This range agrees with the reported experimental data of 25,45 and $90 \mathrm{mmol}$ represented with the green, blue, and yellow color cross marks. Thus, these results are in line with claims from others [62-64] showing that keeping air relative humidity in the $20-50 \%$ range results in a lack of influence of humidity on photocatalytic activity. Therefore, under the proposed conditions, one can process a VOC air contaminated stream with a $30-50 \% \mathrm{RH}$. This is the recommended $\mathrm{RH}$ for indoor environments for air quality $[65,66]$.

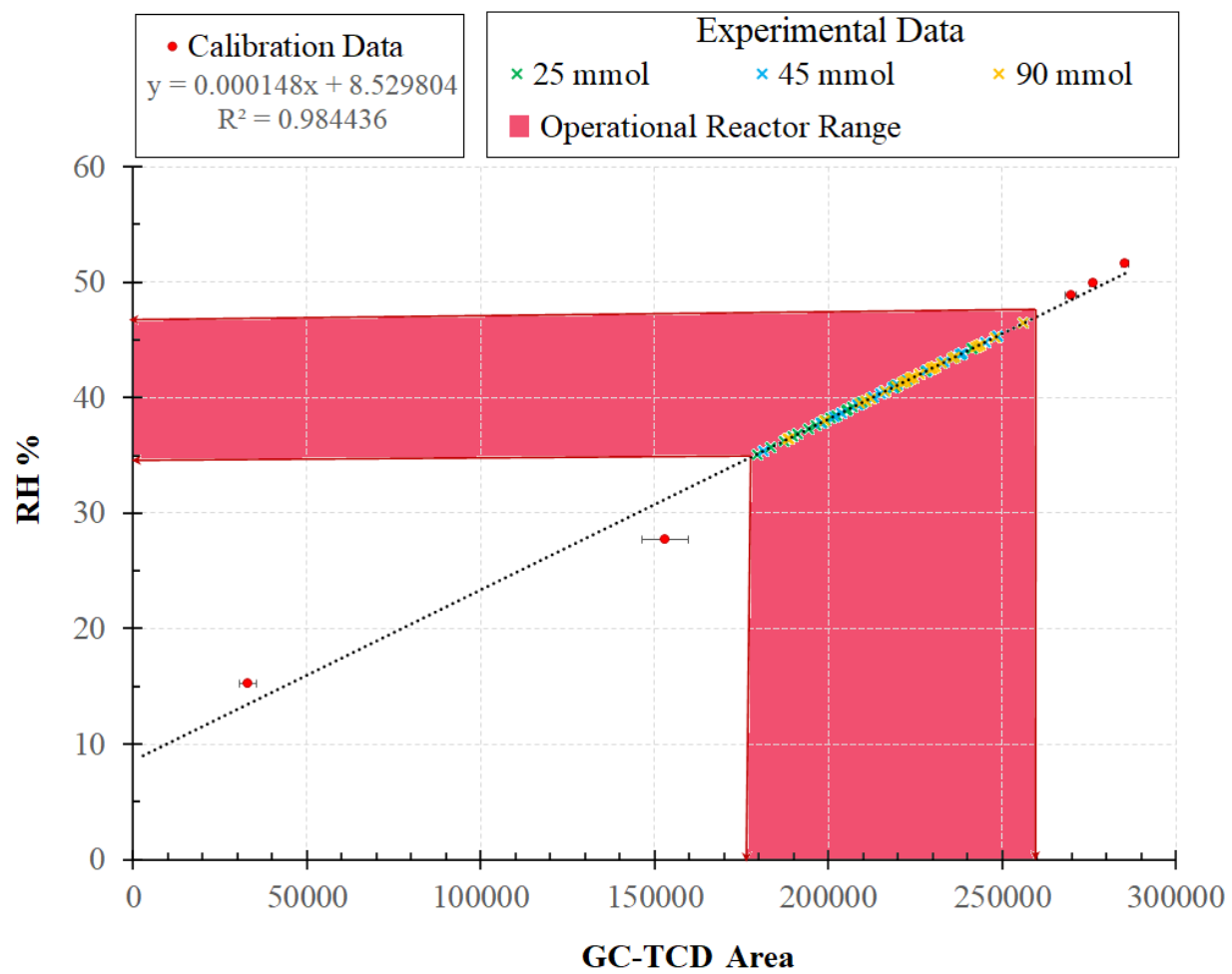

Figure A2. Calibration curve and operational range (pink band) representing relative humidity $(\mathrm{RH} \%)$ for all measurements developed in Photo-CREC-Air Reactor at $39 \pm 0.5^{\circ} \mathrm{C}$.

\section{Appendix C. Percentual Quantum Yield (QY\%) Calculations}

This provide an example \%QY calculation for a $2 \mathrm{wt} . \% \mathrm{~N} / \mathrm{Ag} / \mathrm{TiO}_{2}$ photocatalyst coated on a mesh to degrade $90 \mu \mathrm{mol} / \mathrm{L}$ of methanol under visible light irradiation for $120 \mathrm{~min}$.

$$
\begin{gathered}
\mathrm{CH}_{3} \mathrm{OH}+6 \mathrm{HO}^{\bullet} \rightarrow \mathrm{CO}_{2}+5 \mathrm{H}_{2} \mathrm{O} \\
\% Q Y=\frac{\left[\frac{d N_{\mathrm{OH}} \bullet}{d t}\right]}{P_{a b s}} \times 100 \\
\% Q Y=\frac{6 \times 4.2 \times 10^{-1} \frac{\mu \mathrm{mol}}{\mathrm{L} \cdot \mathrm{min}} \times 55 \mathrm{~L} \times \frac{1 \mathrm{~mol}}{10^{6} \mu \mathrm{mol}} \times 6.02 \times 10^{23} \frac{\text { photon }}{\mathrm{mol}} \times \frac{1 \mathrm{~min}}{60 \mathrm{~s}}}{3.95 \times 10^{18} \frac{\mathrm{photon}}{\mathrm{s}}} \times 100 \\
\% Q Y=35.08 \%
\end{gathered}
$$




\section{Appendix D. The X-ray Photoelectron Spectroscopy (XPS) Spectra of the $\mathrm{N} / \mathrm{Ag} / \mathrm{TiO}_{2}$ Photocatalysts}

Figure $\mathrm{A} 3 \mathrm{a}$ reports the XPS for both $\mathrm{N} / \mathrm{Ag} / \mathrm{TiO}_{2}$ and bare- $\mathrm{TiO}_{2}$ photocatalysts, showing the $\mathrm{Ag} 3 \mathrm{~d}$ and $\mathrm{N}$ 1s peaks for the $\mathrm{N} / \mathrm{Ag} / \mathrm{TiO}_{2}$ photocatalyst only, with these peaks being absent for the bare- $\mathrm{TiO}_{2}$. Thus, the $\mathrm{Ag} 3 \mathrm{~d}$ as well as $\mathrm{N} 1$ s signals confirm the coexistence of $\mathrm{Ag}$ and $\mathrm{N}$ dopants in the photocatalyst.

\section{(a)}

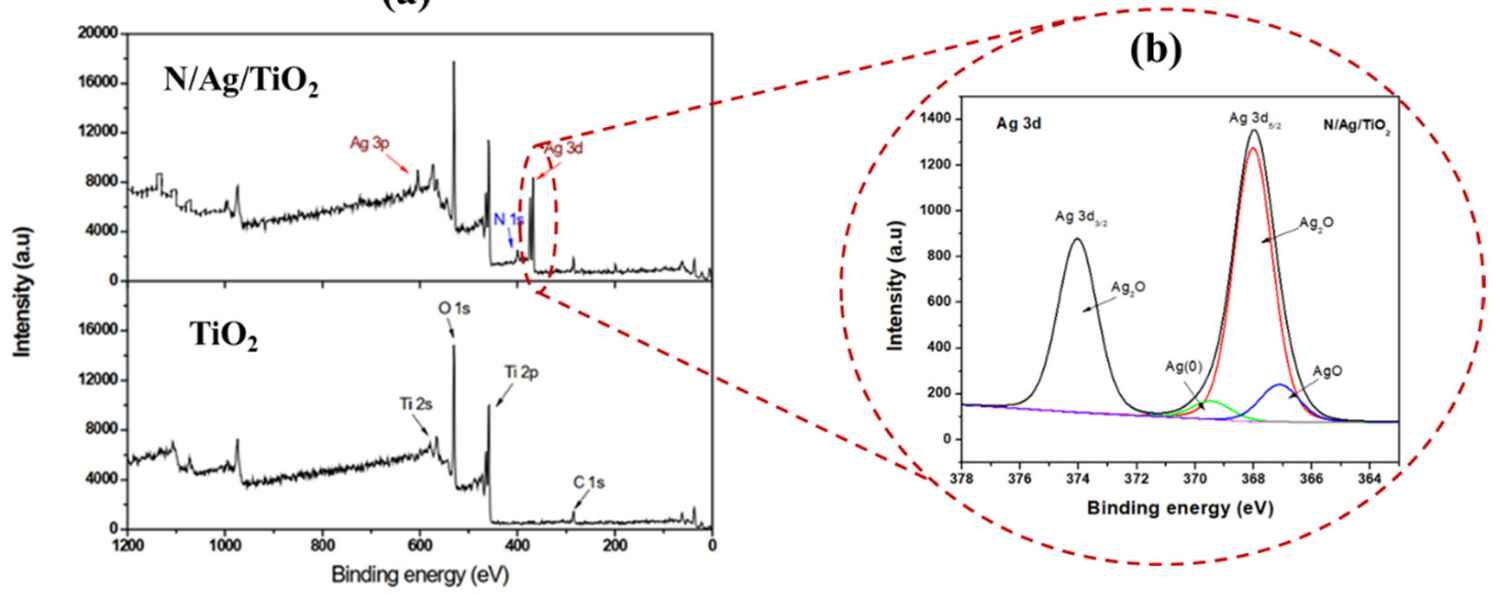

Figure A3. Shows the following: (a) Full scan XPS spectra of $\mathrm{N} / \mathrm{Ag} / \mathrm{TiO}_{2}$ and $\mathrm{Bare}-\mathrm{TiO}_{2}$ photocatalysts and (b) highresolution XPS spectra of Ag 3d.

Regarding Ag 3d peak intensity and peak separation as reported in Figure A3b, this is in good agreement with the finding of others such as Zielinska et al., (2010), Albiter et al., (2015), Fahmy et al., (2017), and Rolim et al., (2020) [53,67-69].

Thus, on this basis one can consider: (a) $\mathrm{N}$ incorporated in the $\mathrm{TiO}_{2}$ lattice, (b) since the $115 \mathrm{pm} \mathrm{Ag}^{+}$ionic radius is larger than the $60.5 \mathrm{pm} \mathrm{Ti}^{4+}$ it can be argued that $\mathrm{Ag}^{+}$is not incorporated into the bare- $\mathrm{TiO}_{2}$ lattice but deposited on the bare- $\mathrm{TiO}_{2}$ surface [70].

\section{References}

1. Ozturk, B.; Yilmaz, D. Absorptive removal of volatile organic compounds from flue gas streams. Process Saf. Environ. Prot. 2006, 84, 391-398. [CrossRef]

2. Zhang, Y.; Chai, X.-S.; Huang, L.; Chen, L.; Hu, H.-C.; Tian, Y.-X. Modeling and prediction of methanol air release from bleached chemi-thermo mechanical pulp board. RSC Adv. 2018. [CrossRef]

3. Hauser, W.A.; Ng, S.K.C.; Brust, J.C.M. Alcohol, Seizures, and Epilepsy. Epilepsia 1988, 29, S66-S78. [CrossRef]

4. Dasgupta, A.; Wahed, A. Testing for Ethyl Alcohol (Alcohol) and Other Volatiles. In Clinical Chemistry, Immunology and Laboratory Quality Control; Elsevier: Amsterdam, The Netherlands, 2014; pp. 317-335.

5. Jahan, K.; Mahmood, D.; Fahim, M. Effects of methanol in blood pressure and heart rate in the rat. J. Pharm. Bioallied Sci. 2015, 7. [CrossRef] [PubMed]

6. Hovda, K.E.; McMartin, K.; Jacobsen, D. Methanol and Formaldehyde Poisoning. In Critical Care Toxicology: Diagnosis and Management of the Critically Poisoned Patient; Brent, J., Burkhart, K., Dargan, P., Hatten, B., Megarbane, B., Palmer, R., White, J., Eds.; Springer International Publishing: Cham, Switzerland, 2017; pp. 1-18. ISBN 978-3-319-20790-2.

7. Yan, T.; Long, J.; Shi, X.; Wang, D.; Li, Z.; Wang, X. Efficient Photocatalytic Degradation of Volatile Organic Compounds by Porous Indium Hydroxide Nanocrystals. Environ. Sci. Technol. 2010, 44, 1380-1385. [CrossRef] [PubMed]

8. Zou, W.; Gao, B.; Ok, Y.S.; Dong, L. Integrated adsorption and photocatalytic degradation of volatile organic compounds (VOCs) using carbon-based nanocomposites: A critical review. Chemosphere 2019, 218, 845-859. [CrossRef]

9. Escobedo, S.; de Lasa, H. Photocatalysis for Air Treatment Processes: Current Technologies and Future Applications for the Removal of Organic Pollutants and Viruses. Catalysts 2020, 10, 966. [CrossRef]

10. Shin Koe, W.; Wen Lee, J; Chan Chong, W.; Ling Pang, Y.; Ching Sim, L. An overview of photocatalytic degradation: Photocatalysts, mechanisms, and development of photocatalytic membrane. Environ. Sci. Pollut. Res. 2020, 27, 2522-2565. [CrossRef]

11. Skocaj, M.; Filipic, M.; Petkovic, J.; Novak, S.; Novak, S.; Stefan, J. Titanium dioxide in our everyday life; is it safe? Radiol. Oncol. 2011, 45, 227-247. [CrossRef] [PubMed] 
12. Manangon-Perugachi, L.E.; Smeets, V.; Vivian, A.; Kainthla, I.; Eloy, P.; Aprile, C.; Debecker, D.P.; Gaigneaux, E.M. Mesoporous Methyl-Functionalized Titanosilicate Produced by Aerosol Process for the Catalytic Epoxidation of Olefins. Catalysts 2021, 11, 196. [CrossRef]

13. Sirivallop, A.; Areerob, T.; Chiarakorn, S. Enhanced Visible Light Photocatalytic Activity of N and Ag Doped and Co-Doped TiO 2 Synthesized by Using an In-Situ Solvothermal Method for Gas Phase Ammonia Removal. Catalysts 2020, 10, 251. [CrossRef]

14. Miyauchi, M.; Ikezawa, A.; Tobimatsu, H.; Irie, H.; Hashimoto, K. Zeta potential and photocatalytic activity of nitrogen doped $\mathrm{TiO}_{2}$ thin films. Phys. Chem. Chem. Phys. 2004, 6, 865-870. [CrossRef]

15. Lugo-Vega, C.S.; Moreira, J.; Serrano-Rosales, B.; de Lasa, H. Kinetics of the pollutant photocatalytic conversion in a Photo-CRECAir Reactor. Chem. Eng. J. 2017, 317, 1069-1082. [CrossRef]

16. Yu, J.; Liu, Z.; Zhang, H.; Huang, T.; Han, J.; Zhang, Y.; Chong, D. Synergistic effect of N- and F-codoping on the structure and photocatalytic performance of $\mathrm{TiO}_{2}$. J. Environ. Sci. 2015, 28. [CrossRef]

17. Hassan, M.S. One Pot Synthesis of $\mathrm{CoTiO}_{3}-\mathrm{TiO}_{2}$ Composite Nanofibers and its Application in Dye Degradation. Int. J. Chemoinform. Chem. Eng. 2019, 8, 47-56. [CrossRef]

18. Kočí, K.; Troppová, I.; Edelmannová, M.; Starostka, J.; Matějová, L.; Lang, J.; Reli, M.; Drobná, H.; Rokicińska, A.; Kuśtrowski, P.; et al. Photocatalytic decomposition of methanol over $\mathrm{La} / \mathrm{TiO}_{2}$ materials. Environ. Sci. Pollut. Res. 2018, 25, 34818-34825. [CrossRef]

19. De Lasa, H.; Serrano, B.; Salaices, M. Photocatalytic Reaction Engineering; Springer US: Boston, MA, USA, 2005; ISBN 978-1-44193627-1.

20. Elmehasseb, I.; Kandil, S.; Elgendy, K. Advanced visible-light applications utilizing modified Zn-doped $\mathrm{TiO}_{2}$ nanoparticles via non-metal in situ dual doping for wastewater detoxification. Optik 2020, 213, 164654. [CrossRef]

21. Gogoi, D.; Namdeo, A.; Golder, A.K.; Peela, N.R. Ag-doped $\mathrm{TiO}_{2}$ photocatalysts with effective charge transfer for highly efficient hydrogen production through water splitting. Int. J. Hydrog. Energy 2020, 45, 2729-2744. [CrossRef]

22. Garcia-Hernandez, J.M.; Serrano-Rosales, B.; de Lasa, H. Energy Efficiencies in a Photo-CREC-Air Reactor: Conversion of Model Organic Pollutants in Air. Ind. Eng. Chem. Res. 2012, 51, 5715-5727. [CrossRef]

23. Gomathi Devi, L.; Narasimha Murthy, B. Characterization of $\mathrm{Mo}$ Doped $\mathrm{TiO}_{2}$ and Its Enhanced Photo Catalytic Activity Under Visible Light. Catal. Lett. 2008, 125. [CrossRef]

24. Chiodo, L.; García-Lastra, J.M.; Iacomino, A.; Ossicini, S.; Zhao, J.; Petek, H.; Rubio, A. Self-energy and excitonic effects in the electronic and optical properties of TiO2 crystalline phases. Phys. Rev. B 2010, 82, 12. [CrossRef]

25. Deloid, G.; Cohen, J.M.; Darrah, T.; Derk, R.; Rojanasakul, L.; Pyrgiotakis, G.; Wohlleben, W.; Demokritou, P. ARTICLE Estimating the effective density of engineered nanomaterials for in vitro dosimetry. Nat. Commun. 2014, 5, 10. [CrossRef] [PubMed]

26. Xing, J.; Li, Y.H.; Jiang, H.B.; Wang, Y.; Yang, H.G. The size and valence state effect of Pt on photocatalytic $\mathrm{H}_{2}$ evolution over platinized $\mathrm{TiO}_{2}$ photocatalyst. Int. J. Hydrog. Energy 2014, 39, 1237-1242. [CrossRef]

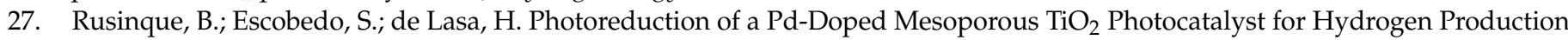
under Visible Light. Catalysts 2020, 10, 74. [CrossRef]

28. Rusinque, B.; Escobedo, S.; de Lasa, H. Photocatalytic Hydrogen Production Under Near-UV Using Pd-Doped Mesoporous TiO 2 and Ethanol as Organic Scavenger. Catalysts 2019, 9, 33. [CrossRef]

29. Pielaszek, J. X-ray Diffraction from Nanostructured Materials. In Nanostructured Materials; Kluwer Academic Publishers: Boston, MA, USA, 2005; pp. 127-143.

30. Liu, Y.; Chen, X.; Li, J.; Burda, C. Photocatalytic degradation of azo dyes by nitrogen-doped $\mathrm{TiO}_{2}$ nanocatalysts. Chemosphere 2005, 61, 11-18. [CrossRef] [PubMed]

31. Bokuniaeva, A.O; Vorokh, A.S. Estimation of particle size using the Debye equation and the Scherrer formula for polyphasic $\mathrm{TiO}_{2}$ powder. J. Phys. Conf. Ser. 2019, 1410, 6. [CrossRef]

32. Yang, S.; Huang, N.; Jin, Y.M.; Zhang, H.Q.; Su, Y.H.; Yang, H.G. Crystal shape engineering of anatase $\mathrm{TiO}_{2}$ and its biomedical applications. CrystEngComm 2015, 17, 13. [CrossRef]

33. Agyeman, D.A.; Song, K.; Kang, S.H.; Jo, M.R.; Cho, E.; Kang, Y.-M. An improved catalytic effect of nitrogen-doped TiO 2 nanofibers for rechargeable $\mathrm{Li}-\mathrm{O}_{2}$ batteries; the role of oxidation states and vacancies on the surface. J. Mater. Chem. A 2015, 3. [CrossRef]

34. Mogal, S.I.; Gandhi, V.G.; Mishra, M.; Tripathi, S.; Shripathi, T.; Joshi, P.A.; Shah, D.O. Single-Step Synthesis of Silver-Doped Titanium Dioxide: Influence of Silver on Structural, Textural, and Photocatalytic Properties. Ind. Eng. Chem. Res. 2014, 53, 5749-5758. [CrossRef]

35. Wen, J.; Li, X.; Liu, W.; Fang, Y.; Xie, J.; Xu, Y. Photocatalysis fundamentals and surface modification of $\mathrm{TiO}_{2}$ nanomaterials. Chin. J. Catal. 2015, 36, 2049-2071. [CrossRef]

36. Wang, Y.; Li, L.; Huang, X.; Li, Q.; Li, G. New insights into fluorinated $\mathrm{TiO}_{2}$ (brookite, anatase and rutile) nanoparticles as efficient photocatalytic redox catalysts. RSC Adv. 2015, 5, 34302-34313. [CrossRef]

37. Pellegrino, F.; Pellutiè, L.; Sordello, F.; Minero, C.; Ortel, E.; Hodoroaba, V.-D.; Maurino, V. Influence of agglomeration and aggregation on the photocatalytic activity of $\mathrm{TiO}_{2}$ nanoparticles. Appl. Catal. B Environ. 2017, 216. [CrossRef]

38. Chen, F.; Johnston, R.L. Plasmonic properties of silver nanoparticles on two substrates. Plasmonics 2009, 4, 147-152. [CrossRef]

39. Liao, C.; Li, Y.; Tjong, S.C. Visible-light active titanium dioxide nanomaterials with bactericidal properties. Nanomaterials 2020, 10, 124. [CrossRef] 
40. Serra, A.; Manno, D.; Buccolieri, A.; Carbone, G.G.; Calcagnile, L. Photochromic properties in silver-doped titania nanoparticles. Mater. Res. Express 2019, 6. [CrossRef]

41. Yang, Y.; Liu, E.; Dai, H.; Kang, L.; Wu, H. Photocatalytic activity of Ag- $\mathrm{TiO}_{2}$-graphene ternary nanocomposites and application in hydrogen evolution by water splitting. Int. J. Hydrog. Energy 2013, 39, 7664-7671. [CrossRef]

42. Nie, J.; Schneider, J.; Sieland, F.; Bahnemann, D.W. New insights into the surface plasmon resonance (SPR) driven photocatalytic $\mathrm{H}_{2}$ production of $\mathrm{Au}-\mathrm{TiO}_{2}$. RSC Adv. 2018, 2, 25881-25887. [CrossRef]

43. Zhang, Z.; Wang, W.; Gao, E.; Sun, S.; Zhang, L. Photocatalysis Coupled with Thermal Effect Induced by SPR on Ag-Loaded $\mathrm{Bi}_{2} \mathrm{WO}_{6}$ with Enhanced Photocatalytic Activity. J. Phys. Chem. C 2012, 116, 25898-25903. [CrossRef]

44. Bakar, S.A.; Ribeiro, C. Nitrogen-doped titanium dioxide: An overview of material design and dimensionality effect over modern applications. J. Photochem. Photobiol. C Photochem. Rev. 2016, 27, 1-29. [CrossRef]

45. Batalović, K.; Bundaleski, N.; Radaković, J.; Abazović, N.; Mitrić, M.; Silva, R.A.; Savić, M.; Belošević-Čavor, J.; Rakočević, Z.; Rangel, C.M. Modification of $\mathrm{N}$-doped $\mathrm{TiO}_{2}$ photocatalysts using noble metals (Pt, Pd)—A combined XPS and DFT study. Phys. Chem. Chem. Phys. 2017, 19, 7062-7071. [CrossRef]

46. Bharti, B.; Kumar, S.; Lee, H.-N.; Kumar, R. Formation of oxygen vacancies and $\mathrm{Ti}^{3+}$ state in $\mathrm{TiO}_{2}$ thin film and enhanced optical properties by air plasma treatment. Sci. Rep. 2016, 6, 12. [CrossRef] [PubMed]

47. Yang, X.H.; Fu, H.T.; Wang, X.C.; Yang, J.L.; Jiang, X.C.; Yu, A.B. Synthesis of silver-titanium dioxide nanocomposites for antimicrobial applications. J. Nanopart. Res. 2014, 2526, 13. [CrossRef]

48. Dozzi, M.V.; Selli, E. Doping $\mathrm{TiO}_{2}$ with p-block elements: Effects on photocatalytic activity. J. Photochem. Photobiol. C Photochem. Rev. 2013, 14, 13-28. [CrossRef]

49. Lynch, J.; Giannini, C.; Cooper, J.K.; Loiudice, A.; Sharp, I.D.; Buonsanti, R. Substitutional or Interstitial Site-Selective Nitrogen Doping in $\mathrm{TiO}_{2}$ Nanostructures. J. Phys. Chem. C 2015, 119, 29. [CrossRef]

50. Kumar, S.G.; Devi, L.G. Review on Modified $\mathrm{TiO}_{2}$ Photocatalysis under UV/Visible Light: Selected Results and Related Mechanisms on Interfacial Charge Carrier Transfer Dynamics. J. Phys. Chem. A 2011, 115, 13211-13241. [CrossRef]

51. Pisarek, M.; Krawczyk, M.; Hołdyński, M.; Lisowski, W. Plasma Nitriding of $\mathrm{TiO}_{2}$ Nanotubes: N-Doping In Situ Investigations Using XPS. ACS Omega 2020, 5. [CrossRef]

52. Tao, X.U.; Mo, W.; Tong, W. Effects of N Doping on the Microstructures and Optical Properties of TiO 2 . J. Wuhan Univ. Technol. Sci. Ed. 2019, 34, 55-63. [CrossRef]

53. Zielińska, A.; Kowalska, E.; Sobczak, J.W.; Łącka, I.; Gazda, M.; Ohtani, B.; Hupka, J.; Zaleska, A. Silver-doped TiO2 prepared by microemulsion method: Surface properties, bio- and photoactivity. Sep. Purif. Technol. 2010, 72, 309-318. [CrossRef]

54. Seery, M.K.; George, R.; Floris, P.; Pillai, S.C. Silver doped titanium dioxide nanomaterials for enhanced visible light photocatalysis. J. Photochem. Photobiol. A Chem. 2007, 189. [CrossRef]

55. Santos, L.M.; Machado, W.A.; França, M.D.; Borges, K.A.; Paniago, R.M.; Patrocinio, A.O.T.; Machado, A.E.H. Structural characterization of Ag-doped $\mathrm{TiO}_{2}$ with enhanced photocatalytic activity. RSC Adv. 2015, 5. [CrossRef]

56. Lv, Q.; Ren, X.; Liu, L.; Guan, W.; Liu, A. Theoretical investigation of methanol oxidation on Pt and PtNi catalysts. Ionics 2019. [CrossRef]

57. Lugo-Vega, C.S.; Serrano-Rosales, B.; de Lasa, H. Energy efficiency limits in Photo-CREC-Air photocatalytic reactors. Chem. Eng. Sci. 2016, 156. [CrossRef]

58. Makuła, P.; Pacia, M.; Macyk, W. How To Correctly Determine the Band Gap Energy of Modified Semiconductor Photocatalysts Based on UV-Vis Spectra. J. Phys. Chem. Lett. 2018, 9, 6814-6817. [CrossRef]

59. Lugo-Vega, C.S.; Serrano-Rosales, B.; de Lasa, H. Immobilized particle coating for optimum photon and $\mathrm{TiO}_{2}$ utilization in scaled air treatment photo reactors. Appl. Catal. B Environ. 2016, 198. [CrossRef]

60. Escobedo Salas, S.; Serrano Rosales, B.; de Lasa, H. Quantum yield with platinum modified $\mathrm{TiO}_{2}$ photocatalyst for hydrogen production. Appl. Catal. B Environ. 2013, 140-141, 523-536. [CrossRef]

61. Escobedo, S.; Rusinque, B.; de Lasa, H. Photochemical Thermodynamic Efficiency Factors (PTEFs) for Hydrogen Production Using Different $\mathrm{TiO}_{2}$ Photocatalysts. Ind. Eng. Chem. Res. 2019, 58. [CrossRef]

62. Zhang, L.; Moralejo, C.; Anderson, W.A. A review of the influence of humidity on photocatalytic decomposition of gaseous pollutants on $\mathrm{TiO}_{2}$-based catalysts. Can. J. Chem. Eng. 2020, 98, 263-273. [CrossRef]

63. Kim, J.S.; Leet, T.K. Effect of Humidity on the Photocatalytic Degradation of Trichloroethylene in Gas Phase over TiO 2 Thin Films Treated by Different Conditions. Korean J. Chem. Eng. 2001, 18, 935-940. [CrossRef]

64. Obee, T.N.; Brown, R.T. $\mathrm{TiO}_{2}$ Photocatalysis for Indoor Air Applications: Effects of Humidity and Trace Contaminant Levels on the Oxidation Rates of Formaldehyde, Toluene and 1,3-Butadiene. Environ. Sci. Technol. 1995, 29, 1223-1231. [CrossRef]

65. Humidifiers: Air Moisture Eases Skin, Breathing Symptoms-Mayo Clinic. Available online: https://www.mayoclinic.org/ diseases-conditions/common-cold/in-depth/humidifiers/art-20048021 (accessed on 25 March 2021).

66. The Ideal Indoor Humidity Level for Your Home I HVAC.com ${ }^{\circledR}$. Available online: https://www.hvac.com/faq/recommendedhumidity-level-home/ (accessed on 25 March 2021).

67. Albiter, E.; Valenzuela, M.A.; Alfaro, S.; Valverde-Aguilar, G.; Martínez-Pallares, F.M. Photocatalytic deposition of Ag nanoparticles on $\mathrm{TiO}_{2}$ : Metal precursor effect on the structural and photoactivity properties. J. Saudi Chem. Soc. 2015, 19, 563-573. [CrossRef] 
68. Rolim, W.R.; Pieretti, J.C.; Renó, D.L.S.; Lima, B.A.; Nascimento, M.H.M.; Ambrosio, F.N.; Lombello, C.B.; Brocchi, M.; De Souza, A.C.S.; Seabra, A.B. Antimicrobial Activity and Cytotoxicity to Tumor Cells of Nitric Oxide Donor and Silver Nanoparticles Containing PVA/PEG Films for Topical Applications. ACS Appl. Mater. Interfaces 2019. [CrossRef]

69. Fahmy, A.; El-Nasser, K.S.; Ali, I.O.; Salama, T.M.; Altmann, K.; Friedrich, J. Tuned interactions of silver nanoparticles with ZSM-5 zeolite by adhesion-promoting poly(acrylic acid) deposited by electrospray ionization (ESI). J. Adhes. Sci. Technol. 2017, 31, 2641-2656. [CrossRef]

70. Yuan, R.; Zhou, B.; Hua, D.; Shi, C. Effect of metal ion-doping on characteristics and photocatalytic activity of TiO 2 nanotubes for removal of humic acid from water. Front. Environ. Sci. Eng. 2015, 9, 850-860. [CrossRef] 